\title{
COLORADOSCHOOLOFMINES
}

EARTH・ENERGY•ENVIRONMENT

Division OF ECONOMICS AND BUSINESS

WORKING PAPER SERIES

\section{Carpooling and Driver Responses to Fuel Price Changes: Evidence from Traffic Flows in Los Angeles}

\author{
Antonio M. Bento \\ Jonathan E. Hughes \\ Daniel T. Kaffine
}

\author{
Working Paper 2012-06 \\ http://econbus.mines.edu/working-papers/wp201206.pdf \\ Colorado School of Mines \\ Division of Economics and Business \\ 1500 Illinois Street \\ Golden, CO 80401
}

August 2012

(c) 2012 by the listed authors. All rights reserved. 
Colorado School of Mines

Division of Economics and Business

Working Paper No. 2012-06

August 2012

Title:

Carpooling and Driver Responses to Fuel Price Changes: Evidence from Traffic Flows in Los Angeles*

Author(s):

Antonio M. Bento

Charles H. Dyson School of Applied Economics and Management

Cornell University

amb396@cornell .edu

Jonathan E. Hughes

Department of Economics

University of Colorado at Boulder

jonathan.e.hughes@colorado.edu

Daniel T. Kaffine

Division of Economics and Business

Colorado School of Mines

Golden, CO 80401-1887

dkaffine@mines .edu

\begin{abstract}
Understanding how drivers respond to fuel price changes has important implications for highway congestion, accidents, carbon policy, local air pollution and taxation. We examine the underexplored relationship between fuel prices and carpooling. Using a simple theoretical model we show that traffic flows in mainline lanes decrease when fuel prices increase. However in carpool (HOV) lanes, flow can either increase or decrease. Traffic flows in mainline lanes are shown to be more responsive to price changes when the presence of a carpool lane provides a substitute to driving alone. We test these predictions using eight years of traffic data for 1,700 locations in Los Angeles. The mean elasticity of flow with respect to fuel price is 0.136 for HOV lanes. This implies 10 additional carpools per hour for a 10 percent increase in fuel price. For mainline lanes, flow elasticities are -0.083 and -0.050 for highways with and without an HOV lane. These estimates imply that the mean highway with an HOV lane experiences a 30 percent larger decrease in hourly flow compared to the mean highway without an HOV lane. Flows in HOV lanes show an immediate decrease following a price increase but respond positively to price increases over time, which suggests time is an important input to carpool formation.
\end{abstract}

Keywords: gasoline prices, traffic congestion, carpooling .

* The authors thank Yahya Faissal Anouti, Martin Boileau, Harrison Fell, Terra McKinnish, Andrew Waxman and seminar participants at Cornell University, the Colorado School of Mines, and the University of California Energy Institute. 


\section{Introduction}

Urban planners have promoted carpool or high occupancy vehicle (HOV) lanes as a second best approach to mitigating traffic congestion when optimal congestion pricing is unavailable. Proponents of HOV lanes have also argued that carpooling may help to reduce a variety of other driving-related social costs, for example, greenhouse gas emissions, local air pollution and highway fatalities. While HOV lanes have received some attention in the theoretical literature, less is known empirically about driver behavior when carpool lanes are present. ${ }^{1}$ An important question is how carpool formation responds to changes in the cost of driving, in particular fuel costs. Increasing oil prices or policies such as renewable fuel standards, carbon taxes or cap and trade systems may impact fuel prices. Furthermore, some economists have argued for increased gasoline taxes as a measure to correct other driving-related externalities. ${ }^{2}$ If higher fuel prices cause more drivers to form carpools, the result may be fewer vehicles on the road, lower congestion, fewer emissions and fatalities.

In this paper we combine theory with empirical analysis to better understand carpool behavior. We begin by developing a simple theoretical framework for commuters' mode choice. Our approach is an equilibrium sorting model where commuters weigh fuel expenditures, time costs on congested highways, and fixed transaction costs of carpool formation against their preferences for driving and costs of alternative options. We find that, not surprisingly, higher fuel prices are associated with decreases in traffic flows in mainline lanes. However, in HOV lanes, higher fuel prices can result in either increased or decreased traffic flows.

The intuition for this result comes from two competing price effects on the number of drivers choosing the HOV lane. On one hand, higher fuel prices cause drivers who previously traveled alone to form carpools, increasing HOV lane flow. On the other hand, higher fuel prices raise the cost of driving in general, resulting in more commuters choosing alternative options. We show that which effect dominates depends on the heterogeneity in preferences for driving relative to alternative options - increased flow in the HOV lane suggests commuters have a strong enough preference for driving such that higher prices induce substitution into the HOV lane instead of alternative options. $^{3}$ For mainline lanes, we predict that drivers on highways with an HOV lane are more

\footnotetext{
${ }^{1}$ For example, see Johnston and Ceerla (1996), Rodier and Johnston (1997) and Barth and Boriboonsomsin (2008) on HOV lane operations and emissions, and Kwon and Varaiya (2008) on HOV lanes and congestion. Lee (1984) presents a theoretical model for carpool formation. Giuliano, Levine, and Teal (1990) survey drivers to understand whether HOV lanes increase carpooling.

${ }^{2}$ These costs may be directly or indirectly related to gasoline consumption. Absent policies that price these externalities directly, Parry and Small (2005) and Parry, Walls, and Harrington (2007) propose a second-best fuel $\operatorname{tax}$.

${ }^{3}$ In Appendix A.1 we show that these findings are also consistent with the results from a model of utility maxi-
} 
responsive to changes in fuel prices because HOV lane access increases the range of substitution options when fuel prices change. Because this decrease in mainline drivers is offset by an increase in HOV lane use, the net effect on traffic flow can be larger or smaller compared to a highway without an HOV lane, depending on preferences for driving and the number of lanes of each type on a given highway.

We test these predictions using eight years of data from Los Angeles California. We exploit detailed data on traffic flows from California's Freeway Performance Measurement System (PeMS) to construct weekly traffic flows for mainline and high occupancy vehicle (HOV) lanes at over 1,700 locations in Los Angeles. ${ }^{4}$ We combine these data with weekly average retail gasoline prices in the region.

Across a variety of specifications and functional forms we find that higher fuel prices are associated with higher flows in HOV lanes (positive flow elasticity) and lower traffic flows in mainline lanes (negative flow elasticity). In our preferred specification, we estimate an average HOV flow elasticity of 0.136 . This implies an average effect of 10 additional carpools per hour for a $10 \%$ increase in fuel price. For mainline lanes, the decrease in flow is larger on highways with an HOV lane, consistent with our theoretical prediction. In our preferred model, we estimate average flow elasticities of -0.050 and -0.083 for mainline lanes on highways with and without HOV lanes. Our estimates suggest that total traffic flows also decline more on the mean HOV highway compared with the mean highway without an HOV lane.

We extend our main empirical results along several dimensions. First, we explore whether flow elasticities depend on the time of day or day of week of travel. We find that drivers are more responsive to fuel price changes during off-peak periods. We estimate flow elasticities between 0.267 and 0.372 for HOV lanes off-peak. For mainline lanes our estimates range from -0.093 to -0.108 and from -0.087 to -0.092 for mainline lanes on highways with and without an HOV lane off-peak. Flow elasticities during weekend peak and off-peak periods look surprisingly similar to weekdays, consistent with high levels of congestion in the Los Angeles area regardless of the day of the week.

Next, we investigate whether time is an input to carpool formation. We do this by estimating several models that aim to isolate the short-run and longer-run responses to fuel price changes. We find that flows in HOV lanes on average decrease in response to increases in the current price of

mization for consumers who choose consumption, labor supply and commuting mode, where driving and not driving are imperfect substitutes.

${ }^{4}$ High occupancy vehicle (HOV) lanes are highway lanes where access is restricted to vehicles carrying more than one occupant. In Los Angeles these restrictions apply 24 hours per day, 7 days per week. 
fuel. However, conditional on this week's price, flows in HOV lanes tend to increase in response to increasing average prices. Flows in mainline lanes on highways without an HOV lane respond to changes in the current week's fuel price, but conditional on current prices do not respond to average prices. For mainline lanes on highways with HOV lanes, flows respond negatively to changes in current prices. The flow response is larger in magnitude when average prices are also rising. The effects in HOV lanes and mainline lanes on highways with HOV lanes are consistent with a short lag in drivers' responses to price changes when carpooling is an option.

Finally, we investigate heterogeneity in our mean elasticity estimates by calculating stationlevel flow elasticities for each location in our sample. While these estimates exhibit substantial variability, the distributions are consistent with our average parameter estimates. We attempt to explain differences in the estimated flow elasticities by correlating the point estimate for each station with observable characteristics of the freeway and surrounding area. For HOV lanes, we find that the (positive) flow elasticities increase as the distance from downtown increases. For mainline lanes we find that flow becomes less elastic the further the distance from downtown Los Angeles and that this effect may be associated with higher incomes in these areas.

Understanding the relationship between carpool formation and fuel prices is important for a number of reasons. First, carpooling reduces the number of vehicles on the road and can lead to reductions in driving-related externalities such as those described above. ${ }^{5}$ Our analysis of Los Angeles shows that higher fuel prices do result in more carpools and fewer vehicles on the road. Second, local governments around the U.S. have made substantial investments in constructing HOV lanes and policies to promote carpooling. ${ }^{6}$ Nationwide there are over 1000 miles of operating HOV lanes in 27 metropolitan statistical areas. ${ }^{7}$ HOV lanes act to encourage carpool formation by reducing travel time for commuters relative to drivers in mainline lanes that face higher levels of congestion and traffic delays. While an analysis of HOV lane construction and highway expansion is beyond the scope of this paper, we show that the presence of an HOV lane may make drivers more responsive to changes in fuel prices, which can result in larger reductions in driving-related externalities when fuel prices rise. Third, understanding carpool behavior provides insight into how commuters weigh fuel costs, time costs and the fixed costs associated with different transportation options. Our analysis suggests that commuters do take these costs into account.

\footnotetext{
${ }^{5}$ For example, price increases that result in decreased vehicle miles traveled can act to reduce local air pollution (Knittel and Sandler, 2011), traffic fatalities (Grabowski and Morrisey, 2006), or congestion (Burger and Kaffine, 2009).

${ }^{6}$ Policy makers may view HOV lane construction as a tool to reduce traffic congestion and automobile related air pollution where congestion tolls are not feasible.

${ }^{7} \mathrm{HOV}$ lane statistics are from the Federal Highway Administration at http://ops.fhwa.dot.gov/freewaymgmt/
} 
This paper also contributes to the large literature estimating price elasticities of fuel demand. Dahl and Sterner (1991) and Espey (1998) survey a long literature dating back to the 1970s. More recent examples document shifts in the relationships between fuel prices and consumption (Hughes, Knittel, and Sperling, 2008) and the effects of price changes on emissions (Davis and Kilian, 2011). Because commuters' responses to fuel price changes can affect the social costs of driving, researchers have begun to focus on particular margins of response. For example, Busse, Knittel, and Zettelmeyer (2010), Klier and Linn (2010), and Li, Timmins, and von Haefen (2010) study fuel prices and vehicle purchase behavior, Blanchard (2009) and Currie and Phung (2007) investigate fuel prices and public transit ridership, while Puller and Greening (1999) focus on overall vehicle miles traveled. This study considers another important response to higher fuel prices in the form of carpooling.

The remainder of this paper is organized as follows. Section 2 describes our theoretical model for predicting driver responses to fuel price increases. Section 3 describes our traffic and fuel price data and Section 4 describes our empirical model. Our main results are presented in 5 and Section 6 concludes.

\section{Theoretical framework}

Here we present a brief theoretical model to conceptualize how changes in gas prices may affect traffic flow. Our analytical exercise utilizes a simple equilibrium sorting model where a fixed number of commuters select their cost-minimizing preferred commute option. ${ }^{8} 9$ Equilibrium is determined by the level of commuting where no agent has an incentive to deviate from their commute choice. We hold both overall highway capacity and the allocation of HOV lanes fixed.

We consider two freeway configurations: In the first, Scenario 1, commuters choose between traveling on $L$ congestible mainline freeway lanes versus an uncongestible alternative commute option (i.e. public transit or telecommuting). In the second configuration, Scenario 2, commuters choose between $L-1$ congestible mainline freeway lanes, a single congestible HOV lane, and an alternative uncongestible commute option. To allow drivers to have heterogenous preferences

\footnotetext{
${ }^{8}$ Our model of commuter choice is similar in spirit to that of Shewmake (2010).

${ }^{9}$ In addition to the model presented here, Appendix A.1 develops a more formal model of household choice, extending Parry and Bento (2001). While the general comparative statics of this more formal model are intractable, we show that in the special case where the marginal utilities of consumption and leisure are constant, the results developed with our equilibrium sorting model mirror those developed with this more formal household model. To verify the analytical results from the equilibrium sorting model, simulation models were run, confirming the derivations below (details available from the authors upon request).
} 
between driving and the alternative option, we consider two cases within each scenario: Case A where the perceived cost of the alternative option is constant across all drivers, and Case B where the perceived cost of the alternative option is uniformly distributed across potential commuters. We stress that the primary purpose of this section is to build intuition regarding gas price responses for the empirical exercise to follow.

For all scenarios and cases, we assume $\bar{N}$ total commuters choose between congestible driving and the alternative option. Drivers pay gas expenses $p \cdot g$ (where $p$ is gas price and $g$ is the exogenous quantity of fuel consumed to travel the route), and incur a travel time cost $T$, which is a function of the number of drivers choosing to use that route and the value of time spent commuting. Costs for the alternative option $A$ are uncongestible and in Case $\mathrm{A}$ are assumed to be constant and exogenous, $A=\bar{A} \cdot{ }^{10}$ In Case $\mathrm{B}$, costs for the alternative option are assumed to be distributed uniformly with mean $\bar{A}$, such that $A \sim U[\bar{A}-b, \bar{A}+b]$ where $b$ represents an arbitrary bound of the distribution $(b=0$ corresponds to Case A).

\subsection{Scenario 1: $L$ congestible mainline freeway lanes and an uncongestible out- side alternative}

Consider a congestible mainline highway with $L$ lanes. Let $N_{m}$ be the number of mainline drivers, $C_{m}$ the number of mainline cars, and $N_{a}$ the number of commuters using the alternative option. Drivers value travel time at $w$, and, for tractability, travel time in a lane is assumed to have the linear form $T=\alpha \cdot C_{m}$, such that travel time increases as more drivers use the highway. ${ }^{11}$ The parameter $\alpha$ captures the effect of adding an additional car to a lane, and thus, with $L$ mainline lanes, travel time will take the form $T=\frac{\alpha}{L} \cdot C_{m}$. Finally, we note that all commuters must choose a route and mainline drivers are assumed to travel alone, such that $N_{m}+N_{a}=\bar{N}$ and $N_{m}=C_{m}$.

\subsubsection{Case 1A: Constant perceived cost of the alternative option}

In this case, commuters compare the total cost of driving with the perceived cost of the alternative option (assumed constant for all commuters), selecting the commuting choice that minimizes:

$$
\min \left\{p \cdot g+w \cdot \frac{\alpha}{L} \cdot C_{m}, \bar{A}\right\}
$$

\footnotetext{
${ }^{10}$ Costs for the alternative option can be thought of as fares and travel time cost plus any costs incurred by not commuting by car. For example, comfort or lost "face time" due to time away from the workplace.

${ }^{11}$ Consistent with the transportation economics literature we consider the value of time $w$ in terms of an equivalent fraction of the wage rate.
} 
Equilibrium in this system simply requires that total costs of driving on the mainline highway equal the alternative option:

$$
p \cdot g+w \cdot \frac{\alpha}{L} \cdot C_{m}=\bar{A}
$$

Solving for equilibrium yields $C_{m}=\frac{L(\bar{A}-p g)}{w \alpha}$ and $N_{a}=\bar{N}-\frac{L(\bar{A}-p g)}{w \alpha}$. Differentiating with respect to gas prices gives: $\frac{d C_{m}}{d p}=-\frac{g L}{w \alpha}$ and $\frac{d N_{a}}{d p}=\frac{g L}{w \alpha}$.

\subsubsection{Case 1B: Heterogenous perceived cost of the alternative option}

In this case, drivers differ in their perceived cost of the alternative option, which is assumed to be uniformly distributed. Commuters will compare the cost of driving against their particular draw of the perceived cost of the alternative option as:

$$
\min \left\{p \cdot g+w \cdot \frac{\alpha}{L} \cdot C_{m}, A \sim U[\bar{A}-b, \bar{A}+b]\right\}
$$

Equilibrium in this system is more complicated than in the prior section. If $\hat{A}$ represents the marginal commuter who, for a given level of congestion, is indifferent between the mainline and alternative option, then commuters with $A>\hat{A}$ will sort to the mainline, while commuters with $A<\hat{A}$ will sort to the alternative option. Given this ordering and the uniform distribution over the alternative option, equilibrium in this system requires that:

$$
p \cdot g+w \cdot \frac{\alpha}{2} \cdot C_{m}=\gamma \cdot N_{a}+\bar{A}-b
$$

Given the assumption of a uniform distribution, costs of the alternative option take on a convenient

linear form where $\gamma=\frac{2 b}{N}$ reflects how quickly perceived costs rise across commuters. Larger $b$ corresponds to more heterogenous costs and a steeper rise across commuters in the costs of the alternative option, while as $b$ approaches $0, \gamma$ goes to zero and costs approach the constant Case A. Solving for the equilibrium for each commute option and differentiating with respect to gas prices yields: $\frac{d C_{m}}{d p}=-\frac{g L}{w \alpha+\gamma L}$ and $\frac{d N_{a}}{d p}=\frac{g L}{w \alpha+\gamma L}$. 


\subsection{Scenario 2: one congestible HOV lane, $L-1$ congestible mainline lanes, and an outside alternative}

Now suppose that one of the $L$ freeway lanes is in fact an HOV lane, such that there is one congestible HOV lane and $L-1$ congestible mainline lanes. We assume that carpool drivers incur a constant transaction cost of $\tau$ to form a carpool, but split the cost of gas evenly. ${ }^{12}$ Let $C_{h}$ be the number of carpools using the HOV lane, and $N_{h}$ be the number of carpoolers, such that $N_{h}=2 C_{h}$. We again assume travel time in a lane takes a linear form, such that in the HOV lane, travel time is given by $T=\alpha \cdot C_{h}$, and in the mainline lanes, travel time is given by $T=\frac{\alpha}{L-1} \cdot C_{m}$. Finally, note that $N_{h}+N_{m}+N_{a}=\bar{N}$.

\subsubsection{Case 2A: Constant perceived cost of the alternative option}

Again, identical commuters compare the total cost of driving (either with another commuter in the HOV lane, or alone in one of the mainline lanes) with the perceived cost of the alternative option (assumed constant for all commuters), selecting the commuting choice that minimizes:

$$
\min \left\{\frac{p \cdot g}{2}+w \cdot \alpha \cdot C_{h}+\tau, p \cdot g+w \cdot \frac{\alpha}{L-1} \cdot C_{m}, \bar{A}\right\}
$$

Equilibrium in this system requires that total costs of driving in the HOV lane and the mainline lane be equal to the alternative option:

$$
\frac{p \cdot g}{2}+w \cdot \alpha \cdot C_{h}+\tau=p \cdot g+w \cdot \frac{\alpha}{L-1} \cdot C_{m}=\bar{A}
$$

Solving for equilibrium yields $C_{h}=\frac{2 \bar{A}-p g-2 \tau}{2 w \alpha}, C_{m}=\frac{(L-1)(\bar{A}-p g)}{w \alpha}$ and $N_{a}=\frac{\bar{N} w \alpha+2 \tau-\bar{A}(L+1)}{w \alpha}$. Differentiating with respect to gas prices gives: $\frac{d C_{h}}{d p}=-\frac{g}{2 w \alpha}, \frac{d C_{m}}{d p}=-\frac{g(L-1)}{w \alpha}$ and $\frac{d N_{a}}{d p}=\frac{g L}{w \alpha}$.

\subsubsection{Case 2B: Heterogenous perceived cost of the alternative option}

In this case, drivers again differ in their perceived cost of the alternative option, which is assumed to be uniformly distributed. Commuters will compare the cost of driving against their particular draw of the perceived cost of the alternative option as:

\footnotetext{
${ }^{12}$ The inclusion of a transaction cost of carpool formation simply reflects the fact that HOV lanes typically have lower travel times than mainline lanes during congested time periods. In the absence of a transaction cost of carpool formation, that wedge in travel time could not persist.
} 


$$
\min \left\{\frac{p \cdot g}{2}+w \cdot \alpha \cdot C_{h}+\tau, p \cdot g+w \cdot \frac{\alpha}{L-1} \cdot C_{m}, A \sim U[\bar{A}-b, \bar{A}+b]\right\}
$$

As in Case 1B above, in equilibrium there will exist a commuter with perceived costs of $\hat{A}$ such that commuters with $A<\hat{A}$ will use the alternative option, while commuters with $A>\hat{A}$ will either use the HOV lane or mainline lanes. Equilibrium is determined by:

$$
\frac{p \cdot g}{2}+w \cdot \alpha \cdot C_{h}+\tau=p \cdot g+w \cdot \frac{\alpha}{L-1} C_{m}=\gamma \cdot N_{a}+\bar{A}-b
$$

Solving and differentiating with respect to gas prices yields: $\frac{d C_{h}}{d p}=-\frac{g(w \alpha+(1-L) \gamma)}{2 w \alpha(w \alpha+(1+L) \gamma)}, \frac{d C_{m}}{d p}=$ $-\frac{g(L-1)(w \alpha+\gamma)}{w \alpha(w \alpha+(1+L) \gamma)}$ and $\frac{d N_{a}}{d p}=\frac{g L}{w \alpha+(1+L) \gamma}$.

\section{$2.3 \quad$ Summary of model predictions}

Here we summarize the above results, presented in table 1. In the simplest case (1A) of only mainline lanes and an alternative option, with constant costs for the alternative option, increasing gas prices decreases mainline drivers and increases the use of the alternative options, as expected. When heterogeneous costs for the alternative option are added in $1 \mathrm{~B}$, the effect of an increase in gas prices is muted relative to the previous case. As a result, there is less substitution away from the mainline freeway towards the outside alternative when gas prices rise.

Scenario 2 changes the freeway configuration to include one HOV lane, $L-1$ mainline lanes and an alternative option. In $2 \mathrm{~A}$, with constant costs of the alternative option, rising gas prices cause flow in both the HOV and mainline lanes to drop, with a smaller decline in the HOV lane. This is intuitive as the cost of using the HOV lane does not increase as much as the cost of using mainline lanes when gas prices increase. Nonetheless, with constant perceived cost of the alternative option, HOV lane use will unambiguously decrease as gas prices increase. However, when heterogeneous costs are added in $2 \mathrm{~B}$, there is less substitution towards the outside alternative when an HOV lane is present, relative to case $2 \mathrm{~A}$. Intuitively, we can think of the heterogenous costs of the alternative option as representing a preference for driving, and because the HOV lane represents a relatively cheaper driving alternative to the mainline, fewer total drivers substitute out of driving entirely. Furthermore, HOV flow may actually increase due to an increase in gas prices compared to 2A, depending on the relative magnitude of $w \alpha$ versus $\gamma$. Larger $\gamma$ corresponds to a larger increase in HOV lane flows - the intuition is that if the perceived cost of the alternative option increases fast enough across commuters, then enough commuters will substitute out of the mainline lane and into 
the HOV lane (instead of into the alternative option) leading to an increase in flow. Similarly, for sufficiently large $\gamma$, the response in the mainline will be larger in the presence of an HOV lane than in Case 1B, as the presence of an HOV lane provides a substitute for the alternative option.

Furthermore, we can also compare the magnitude of the total price effect (and thus say something about changes in externalities like emissions) when an HOV lane is present or not. Subtracting the price effect in case $1 \mathrm{~A}$ from $2 \mathrm{~A}$, we have that $\left(-\frac{g}{2 w \alpha}+-\frac{g(L-1)}{w \alpha}\right)-\left(-\frac{g L}{w \alpha}\right)=\frac{g}{2 w \alpha}$, which is positive. Thus, when the alternative option has constant cost across commuters, the change in total vehicles is unambiguously smaller when an HOV lane is present. When costs are heterogenous, subtracting the price effect in case 1B from $2 \mathrm{~B}$ gives: $\frac{g\left(w^{2} \alpha^{2}+(1+2 L) w \alpha \gamma-(L-1) L \gamma^{2}\right)}{2 w \alpha(w \alpha+L \gamma)(w \alpha+(1+L) \gamma)}$. When $\gamma$ is small, the negative term in the numerator is also small, and the change in total vehicles is smaller when an HOV lane is present. However, with sufficiently large $\gamma$, the numerator is negative, and the change in total vehicles is larger when an HOV lane is present. The intuition is that if $\gamma$ is sufficiently high, then when prices rise in the absence of an HOV lane, few drivers will stop driving, leading to small changes in total vehicles. By contrast, when prices rise in the presence of an HOV lane, commuters still want to continue driving, but they choose to instead drive in the HOV lane. Thus, which configuration leads to a greater change in vehicles boils down to whether or not having a substitute (which still involves some vehicle use) is better than when people are limited to only substituting towards the alternative option (which does not involve vehicle use). ${ }^{13}$

Looking towards the empirical exercise, the model above provides several hypotheses to explore. First, if the change in HOV lane flow due to a gas price increase is positive, then this suggests that commuters do not have identical perceived costs of the alternative option - instead, commuters who prefer to drive will substitute from the mainline lane into the HOV lane rather than use the alternative option. Second, in comparing the mainline response on freeways with and without HOV lanes, mainlines with an accompanying HOV lane should see larger negative response to gas price changes, as the HOV lane provides a lower-priced driving option relative to the mainline lane. ${ }^{14}$ Finally, given the ambiguous predictions of the analytical model, we can also explore how the change in total vehicles varies with freeway configuration to determine whether the decline in vehicles on mainline-only freeways is larger or smaller than the net vehicle change on mainline plus

\footnotetext{
${ }^{13}$ This can also be seen from taking the limit of the price effects in table 1 as $\gamma \rightarrow \infty$. In case $1 \mathrm{~B}$, the limit of the mainline price effect is zero, while in case $2 \mathrm{~B}$, the limit of the sum of the price effects is $g(1-L) /(w \alpha(1+L))<0$. Essentially as substitution towards the alternative option goes to zero, having an HOV lane available would clearly reduce total vehicles, while not having an HOV lane would not.

${ }^{14}$ Our model does not formally consider substitution across routes or substitution between highways and surface streets. Rising fuel prices that reduce congestion enough to entice new drivers to mainline lanes from alternate routes would bias our empirical estimates against finding an effect of fuel prices on mainline flows. For HOV lanes, rising fuel prices that cause drivers who previously traveled via surface streets to form carpools and use the HOV lane would tend to inflate the flow elasticities we estimate in the following sections.
} 
HOV freeways.

Some additional discussion is warranted in terms of relating the additional empirical results (to be presented below) with the analytical exercise above. First, the response to gas prices at different points in the city may be very heterogeneous. Longer commutes are associated with higher gasoline expenditure, and thus we would expect more distant drivers to be more responsive to higher gas prices than those with shorter commutes (all price effects in table 1 are increasing in $g$ ). Similarly, higher values of time tend to mute the response to gas price increases (all price effects in table 1 are decreasing in $w$ ). Access to public transit can also vary throughout the city, influencing commuters willingness to substitute out of driving entirely when gas prices increase. Second, in the above model, the number of commuters is held fixed, while in reality, the number of commuters varies throughout the day and over the course of the week. Intuitively, we would expect more discretionary trips to be taken outside of the main workday commute, thus increasing the response to higher gas prices (for example if higher prices encourage more people to retail online rather than drive to the shopping mall). Finally, the model presented above can be thought of as a steady-state, long-run equilibrium; however, the response by commuters to higher gas prices may not be immediate. In particular, formation and dissolution of carpools may not be an instantaneous action that can be taken in response to short-run fluctuations in gas prices.

\section{Data}

Our empirical analysis exploits detailed data on traffic flows from the California Freeway Performance Measurement System (PeMS). PeMS aggregates data from the state-wide network of highway vehicle sensors (detectors) and reports traffic flows and average vehicle speeds in intervals as small as 30 seconds at over 25,000 locations state-wide. We focus on highway traffic flows in Los Angeles and Ventura counties in Southern California. Los Angeles is widely know to have severe traffic congestion and also one of the most extensive networks of HOV lanes in the nation. ${ }^{15}$ We construct a balanced panel of traffic flows at 1,727 stations over the period from July of 2000 through December of 2007. ${ }^{16}$ Stations fall into one of three categories, HOV lanes (HV), mainline lanes (ML) or mainline lanes on sections of highway that also contain HOV lanes (ML_HV). ${ }^{17}$ We

\footnotetext{
${ }^{15}$ Other major cities, for example San Francisco and Sacramento, have many fewer HOV lanes and in many cases lanes may not be continuous along major routes. Los Angeles County alone has $36 \%$ of all HOV lane-miles in the state of California, with roughly two-thirds of all state HOV lane-miles located in the five county region of Los Angeles, Ventura, Orange, Riverside and San Bernadino counties.

${ }^{16}$ We drop observations for detectors located on on-ramps, off-ramps and freeway interchanges.

${ }^{17}$ Mainline stations are classified as ML_HV if an HOV lane exists somewhere along the route. We classify I-5 stations as ML_HV because the presence of HOV lanes in Orange County likely affected traffic flows in our sample
} 
observe $442 \mathrm{HV}$ stations, $173 \mathrm{ML}$ stations and 1,112 ML_HV stations. ${ }^{18}$ Because we observe weekly fuel prices, described below, we sum hourly flows to the station-week level. ${ }^{19}$

Because we are primarily interested in transportation demand during periods when highways may be congested, our main results focus on the "peak period" from 6:00 am through 8:00 pm, Monday through Friday. ${ }^{20}$ We do this for two reasons. First, externalities such as congestion and air pollution are likely to be more severe during these periods. Understanding carpooling behavior at these times is important for policy makers. Second, observing the population of carpoolers across any large geographic area is difficult. Here we use flow in HOV lanes as a proxy for the total number of carpools on the freeway. Because HOV lanes offer a travel time advantage relative to mainline lines during congested periods, it is likely that the vast majority of carpools use these lanes.

Table 2 presents summary statistics for the weekday peak, weekday off-peak and weekend periods. Gas prices in constant 2005 dollars range between $\$ 1.17$ and $\$ 3.30$ per gallon. ${ }^{21}$ Mean station-level flows range from approximately 309,000 vehicles during the weekday peak period to 28,000 for the weekend off-peak periods. Since the different periods sum over different lengths of time, we also report average hourly flows as a more intuitive measure of traffic flow. Average hourly flows per lane range between 403 and 1,150 vehicles per hour. Comparing weekends and weekdays, mean hourly flow during the peak period is 1,150 vehicles per hour for weekdays and 999 for weekends. Off-peak hourly flows are also similar for weekdays and weekends at approximately 400 vehicles per hour. This suggests that traffic can still be quite congested in Los Angeles even on weekends and that the period of the day is perhaps a more important determinant of the level of congestion than the day of the week.

Figure 1 plots total weekly flows across all stations of a given type versus fuel prices. Gasoline prices in Los Angeles begin relatively flat but increase steadily starting in 2002. The time-series of prices shows strong seasonal patterns with prices increasing throughout the spring, in general

even though I-5 in Los Angeles did not contain HOV lanes prior to 2008. Reclassifying I-5 as a ML highway yields similar results to those presented here.

${ }^{18}$ In our specifications that drop imputed observations, our sample falls to 1,660 stations with $432 \mathrm{HV}, 165$ ML and 1,063 ML_HV.

${ }^{19}$ This approach also substantially reduces the computational burden of our analysis by reducing the sample size from approximately 114 million observations to under 700,000 observations. More importantly, this eliminates the need to model complex daily and hourly station level-trends which, using mean effects, would require the estimation of over 100,000 additional parameters. Furthermore, given that households fill their gas tank roughly once a week, it seems reasonable to assume that commuters respond to changing gas prices on a weekly basis.

${ }^{20}$ Because different highways may have different congestion patterns depending on, for example, the direction of flow, we also experiment with off-peak and peak periods defined by the first and fourth quartiles of station-level mean hourly flows, respectively. These results are presented as a robustness check in Section 5 below.

${ }^{21}$ Prices are adjusted to constant 2005 dollars using CPI deflators for all goods in Los Angeles, Riverside and Orange counties from the U.S. Bureau of Labor Statistics. 
remaining high during the summer months, and decreasing in the fall. Aggregate traffic flows also exhibit similar seasonal patterns with greater flows during the summer months. Focusing on the later period of the sample with higher mean fuel prices, flow in mainline (ML) lanes (panel a) and mainline lanes in highways with HOV (ML_HV) lanes (panel b) appear to decrease slightly during the period from 2006 to $2008 .^{22}$ Flow in HOV (HV) lanes (panel c) increase substantially from 2006 to 2008.

We next investigate the time series properties of our data. Because both traffic flows and fuel prices may be trending over time, one may be concerned about the possibility of spurious relationships in our analysis of traffic flows and fuel prices. We would like to test whether the gasoline price and flow time series are stationary. For fuel prices, since we observe only city-level prices, we have a single time series. We conduct Elliott, Rothenberg, and Stock (1996) unit-root tests for the gasoline price series in levels and logs. Focusing on the Ng-Perron optimal lags, we reject the presence of a unit-root in gasoline prices at the 5-percent level, but fail to reject the presence of a unit-root in log gasoline prices. ${ }^{23}$ For the station-level flow series, the problem is complicated somewhat by the panel nature of our data and the high likelihood of both serial correlation and cross-sectional dependence across stations in our sample. ${ }^{24}$ We conduct augmented Dickey-Fuller Im, Pesaran, and Shin (2003) unit-root tests for both flow and log flow. We assume either one lag or four lags and subtract the cross-section means from the series to help mitigate the impact of cross-sectional dependence. We reject the null hypothesis that all panels contain unit roots in both cases at the 1 percent level. Similarly, we also conduct a Hadri LM test where the null assumes that all series are stationary around a linear trend. In this case, we reject the null that all series are stationary at the 1 percent level.

From these tests we conclude that at least a substantial fraction, though not all, of the stationlevel series are stationary. To verify this, we iterate over all the series in our panel and conduct separate Elliot-Rothenburg-Stock unit-root tests for each station. For 1,317 stations or 76 percent of our sample, these tests fail to reject the presence of a unit root in the flow series at the 5 percent level. $^{25}$

We note that unit root tests of individual cross-sectional units are generally thought to lack

\footnotetext{
${ }^{22}$ The drop in total mainline flows seen in January of 2005 may be the result of imputation which increased during this period. Our main specifications with year fixed effects account for level shifts across years. Estimating models for the periods before and after January 2005 produce results similar to those presented here.

${ }^{23}$ DF-GLS tau test statistics of -3.351 and -2.420 , respectively.

${ }^{24}$ Traffic flows along routes are highly correlated. Furthermore, traffic may be correlated across alternate routes traveling in the same direction.

${ }^{25}$ We fail to reject a unit root for 86 percent of ML station, 82 percent of ML_HV stations and 58 percent of HOV stations.
} 
power when applied in a panel setting. Therefore, the results of our Elliot-Rothenburg-Stock tests are likely an upper bound on the number of non-stationary series. ${ }^{26}$ Furthermore, the presence of cross-sectional correlations in our traffic flow data may also reduce the power of our panel tests. ${ }^{27}$ Because the true extent of non-stationarity in our data is unknown, we proceed with caution, treating all price and flow series as stationary. As a robustness check, Appendix A.2 verifies that using only the stations with stationary series produces results that are qualitatively similar to those presented below. We return to these issues in Section 5.3 where we explore the dynamic properties of traffic responses to fuel price changes and present results estimated in first differences and several alternate specifications.

A final issue relates to imputation in the PeMS data. PeMS engineers rely on two methods of imputing flows when station malfunctions result in missing data. Spatial imputation uses contemporaneous observations from nearby stations to infer missing flow data. Temporal imputation forecasts missing flows using past observations. Spatial imputation may bias the standard errors of our parameter estimates by introducing spatial correlation in the disturbance terms. Temporal imputation may bias our parameter estimates by removing any influence of fuel prices on flows in the forecasted values. We address imputation in two ways. First, our estimates below report cluster robust standard errors clustered at the route-direction level in 5 mile increments to account for spatial common shocks. ${ }^{28}$ Second, our preferred estimates drop observations that include on average more than $25 \%$ imputed observations in a given week. As a robustness check we estimate our model including all imputed observations. Results are qualitatively similar to the restricted sample.

\section{Empirical model}

In the theoretical model in Section 2, equilibrium flow in each lane is a function of gas prices $p$, value of time $w$, fuel consumption over the commute distance $g$, carpool formation $\operatorname{costs} \tau$, congestibility of the freeway $\alpha$, and driving preferences $\gamma$. Because many of these features are unobserved and we are ultimately interested in the change in flow due to changes in gas prices, a reduced-form empirical approach is adopted whereby these unobserved variables are modeled as mean effects.

\footnotetext{
${ }^{26}$ For example, Levin, Lin, and Chu (2002) investigate the asymptotic and finite-sample properties of unit root tests in a panel setting.

${ }^{27}$ For a thorough review of issues related to unit root tests in this setting the reader is referred to Maddala and $\mathrm{Wu}$ (1999).

${ }^{28}$ We are unaware of empirical evidence for the distance over which commuting choices may be correlated. Clustering at the station level, in 10 mile intervals or at the route-direction level produce standard errors similar to those reported below.
} 
Our preferred empirical model regresses the log of weekly flow for station $i$ in week $t$ on the $\log$ of fuel price. In addition, we explore functional forms where either fuel prices alone or fuel prices and flows both enter in levels. Our main results pool stations of all three lane types. We estimate average flow elasticities for ML, ML_HV and HV lanes by interacting an indicator variable for each type with log fuel prices. In alternate specifications presented below, we also calculate station-level elasticities by interacting a set of station dummies with fuel prices, assuming common trends and seasonal effects. In a second specification, we allow each station to have unique week effects and estimate station-level elasticities via separate OLS regressions. In each case, we observe mean elasticities for each lane type that are qualitatively similar to our base model.

Equation 9 below presents our preferred specification. $D_{l}$ is a set of indicator variables for each lane type. The main coefficients of interest are given by the interaction $D_{l} \times \beta_{1}$. We model unobserved factors that affect traffic flows at the station-level as mean effects $\epsilon_{i}$. We model unobserved trends that affect traffic flows as year effects $\epsilon_{y}$ and model seasonal effects using a set of 52 week dummy variables, $\epsilon_{w}$.

$$
\ln \left(\text { flow }_{i t}\right)=\beta_{0}+\sum_{l=1}^{3} D_{l} 1(\text { type }=l)_{i} \times\left[\beta_{1} \ln \left(\text { Pgas }_{t}\right)\right]+\epsilon_{i}+\epsilon_{w}+\epsilon_{y}+\epsilon_{i t}
$$

In a series of alternate specifications below, we explore the robustness of our results to omitting year effects, week effects and adding a time trend. In addition, we explore the possibility that our time and seasonal controls do not adequately account for the potential endogeneity of fuel prices and instrument for Los Angeles gasoline prices with oil prices.

\section{Empirical results}

\subsection{Average peak-period flow elasticities}

We begin by estimating the average flow elasticities with respect to gasoline prices using our pooled data. Table 3 presents results from our preferred specification, Equation 9, as well as several alternate specifications. Model 1 includes station effects and lane-type interactions but excludes time effects. Model 2 adds week effects to capture weekly patterns in traffic flow common to all stations. Model 3 is our preferred specification which includes common week and year effects. Model 4 replaces year effects with a linear time trend. ${ }^{29}$

\footnotetext{
${ }^{29}$ In our robustness checks we investigate higher order time trends to more flexibly capture changes in traffic flows over time. These results are very similar to the estimates presented in Table 3.
} 
The point estimates across these four specifications are qualitatively similar. Flow elasticities in the mainline lanes are negative and statistically significant in specifications that account for common seasonal and time effects. Flow elasticities are larger in magnitude for mainline lanes on highways with an HOV lane (ML_HV) compared with other mainline lanes (ML) consistent with the predictions of our theoretical model. ${ }^{30}$ The mainline flow elasticities can be interpreted as weekly VMT elasticities and are comparable to recent estimates for the short-run elasticity of gasoline demand. For example, Hughes, Knittel, and Sperling (2008) estimate a short-run price elasticity between -0.03 and -0.08 .

For HOV lanes, theory suggests that the flow elasticity may be positive or negative depending on the preferences of commuters for driving. Here, we find the estimated flow elasticities are positive and statistically significant in each of the four specifications. One interpretation of this result is that distaste for not driving is sufficiently large that when fuel prices increase, a larger share of commuters would rather carpool than choose the alternative option.

In our main results, we attempt to limit the impact of imputation in the PeMS data by dropping all weekly observations where the mean level of imputation exceeds 25 percent. Model 5 relaxes this restriction and includes all observations regardless of the level of imputation. When all imputed observations are included, the estimated mainline elasticities are quite similar to the main results in Model 3. However, the estimated flow elasticity for HOV lanes is substantially larger. ${ }^{31}$ While it is comforting that allowing for more imputation does not qualitatively change our findings, in what follows we will limit the level of imputation in our data to below 25 percent. $^{32}$

Looking across the specifications, the estimated mainline elasticities are small in magnitude for models without week and time effects. This is consistent with a bias towards zero introduced by endogenous prices if we fail to account for unobserved (flow) demand shocks. Models 3 and 4 account for mean changes in flow across stations at the week and year level, which appears to at least partially account for demand shocks. To further investigate this issue, the last column of Table 3 presents 2SLS estimates where oil prices are used to instrument for the price of gasoline. Oil prices are plausibly orthogonal to traffic patterns in Los Angeles and also correlated with local

\footnotetext{
${ }^{30}$ We reject the null hypothesis that the estimated elasticities are equivalent with a $p$-value of 0.08 .

${ }^{31}$ If traffic flows only respond to current prices then we would expect temporal imputation to bias the estimated flow elasticities toward zero. However, we provide evidence below that time may be an important input into carpool formation. One possible explanation of the larger estimated HOV effect is that imputed observations capture mainly the (positive) flow response to longer run trends in prices but largely miss the (negative) short run response, introducing a positive bias.

${ }^{32}$ Because stations may use imputed data for short periods throughout the day, and because we are aggregating station-level data over all hours in a given week, limiting imputation completely would substantially reduce our sample size.
} 
gasoline prices. ${ }^{33}$ The 2SLS elasticities are comparable to those in the OLS specifications, though compared with Model 3 the mainline elasticities are smaller in magnitude and the HOV elasticity is somewhat larger. Because the estimates appear quite similar and due to the computational cost of estimating 2SLS is this setting, we limit our analysis in the sections below to OLS. We focus on specifications that include year and week effects, similar to Model 3.

Appendix A.2 investigates the robustness of our main parameter estimates along several additional dimensions. First, we verify that our results our similar using only stations for which we can reject the presence of a unit root in the flow data. Next, we explore implications of our assumed specification in natural logarithms. Finally, we check robustness to the inclusion of higher order time trends. In each case, the estimated flow elasticities are quite similar to those in our preferred specification.

\section{$5.2 \quad$ Peak versus off-peak periods}

Both our theoretical model and main empirical results consider the effects of changes in fuel prices on traffic flows during peak periods when traffic is congested. However, we may observe different behavior in the absence of congestion or during periods when costs of the alternative option are different. To explore behavior in other periods, we construct weekly traffic flows for peak and off-peak periods on both weekdays and weekends. Our main results assume the weekday peak period is from $6 \mathrm{am}$ to $8 \mathrm{pm}$ on Monday through Friday. We define weekday off-peak as 8pm to 6am, Monday through Friday. Weekend peak and off-peak periods use equivalent hours of the day for traffic flows on Saturday and Sunday. Because individual stations may have different peak periods depending on, for example, their distance from downtown or the direction of travel, we alternatively define weekday "peak hours" for each station as the 6 hours with highest average hourly flow and a weekday "off-peak hours" as the 6 hours of lowest average flow. Table 4 summarizes the mean elasticities by lane-type during each of these periods.

We begin with the weekday peak and off-peak periods. The estimated mainline elasticities are larger in magnitude during the off-peak period compared with the peak period. For mainline lanes and mainline lanes on HOV highways, the estimated flow elasticities are -0.092 and -0.108 . For HOV lanes, the estimated average flow elasticity is 0.267 . This is consistent with a larger share of off-peak travel being discretionary, and therefore more able to respond to changes in fuel prices. For HOV lanes, the estimated elasticity is nearly twice as large during the off-peak period. One possible explanation is that the average costs of carpool formation, $\tau$, are lower off-peak due to

\footnotetext{
${ }^{33}$ For oil prices we use the Cushing, OK spot price for WTI crude.
} 
a greater share of trips occurring with friends or family members who share common origins or destinations. However, because drivers of carpools may not preferentially select HOV lanes during uncongested periods, our ability to draw conclusions based on these results is limited. ${ }^{34}$

The trends are similar for the weekend peak and off-peak periods. During peak times, the flow elasticities for the three lane types are comparable to the weekday estimates at -0.058 and -0.077 for ML and ML_HV, and 0.168 for $\mathrm{HOV}$ lanes. This is somewhat surprising given the potential differences in the types of trips made during the week and on weekends. However, the similarity of the estimates suggests that congestion and time costs during peak hours may be similar on both weekdays and weekends. ${ }^{35}$ During the off-peak period, the estimated elasticities for mainline lanes are larger in magnitude compared to weekdays. This is again consistent with a greater portion of this travel being discretionary.

Finally, we investigate our definitions of peak and off-peak. The alternate definition of "peak hours" results in estimates comparable to our main results, though the magnitudes appear slightly smaller. Here as before we reject the null hypothesis that the estimated elasticities for ML and ML_HV lanes are equal. ${ }^{36}$ For off-peak hours, the mainline estimates are similar to those using the common off-peak definition though the estimated flow elasticity in HOV lanes is substantially larger.

\subsection{Dynamic properties of traffic responses}

In this section we explore dynamic responses of traffic flows in mainline and HOV lanes to changes in fuel prices. Section 2 notes that carpool formation may require time to identify other commuters with whom to share a ride. Furthermore, Section 3 suggests both fuel prices and traffic flows, in a substantial fraction of the stations, are trending over time. Here, we further explore these issues. Our motivation is twofold. First, we hope to identify both short-run and longer-run components of the response to fuel price changes. These effects may vary by lane type. Second, we attempt to verify that persistent changes in fuel prices are important for both carpool formation and the associated decreases in flows in mainline lanes on highways with HOV lanes.

Table 5 show the results of several specifications intended to isolate the short-run and longer-run impacts of fuel prices on traffic flows. Model 1 is our main specification from Section 5.1 which relies on within year variation in fuel prices to identify average flow elasticities. In model 2, we

\footnotetext{
${ }^{34}$ For instance, a large share of carpools may travel in mainline lanes off-peak.

${ }^{35}$ This is supported by the high flow levels we observe in the summary statistics for weekend peak hours.

${ }^{36}$ We reject the null hypothesis that these coefficients are equivalent with a $p$-value of 0.06 .
} 
replace weekly fuel prices with monthly average fuel prices constructed as the simple average of the previous four weeks (i.e. excluding the current week). The intent is to limit the impact of weekly variation in prices and isolate aggregate trends that may influence long-run behavior. If consumers are responding to past trends in fuel prices we might expect larger flow elasticities. In this case, the estimated mainline elasticities are smaller in magnitude relative to our base model, though the difference is not statistically significant. This is consistent with a downward bias introduced by measurement error in fuel prices which one might expect if consumers are in fact responding to weekly price changes. For HOV lanes however, the estimated flow elasticity is larger than the base model, though again the difference is not statistically significant. This provides suggestive evidence consistent with carpool formation occurring over a period longer than one week.

The next two models attempt to investigate the short-run traffic responses to changes in fuel prices. We take two different approaches to de-trending the flow and fuel price data. Model 3 presents estimates in first-differences where we subtract from each observed price and flow, both in natural logs, the previous week's observation. Here, positive weekly changes in fuel prices are associated with negative changes in flows in both the mainline and HOV lanes. In model 4, we de-trend fuel prices flows by regressing each series on a constant and a linear time trend. In the results shown in column 4, we regress the residual flows obtained from this procedure on the corresponding de-trended fuel prices. Accounting for trends in this manner, the estimated flow elasticities are -0.045 and -0.077 in the ML and ML_HV lanes. In HOV lanes, the estimated flow elasticity is negative at -0.042 , though not statistically significant.

Model 5 presents parameter estimates from a model intended to capture both the short-run and longer-run responses. We include both weekly fuel prices and monthly average fuel prices. One interpretation of this approach is that of a distributed lag model where the coefficients on lagged fuel prices are constrained to have equal effects on current traffic flows. ${ }^{37}$ In this case, the longer-run effect can be thought of as the sum of the coefficients on current price and monthly average price.

For mainline lanes on highways without HOV lanes, the short-run response captured by current week fuel prices is -0.040 . The elasticity with respect to monthly average prices is small, negative and not statistically significant. This suggests that drivers on these routes respond to fuel price increases primarily in the short-run by choosing the alternative option. For HOV lanes, the shortrun response is -0.094 and statistically significant. However, the elasticity with respect to monthly

\footnotetext{
${ }^{37}$ Specifically, using a simple average of 4 weeks' price, the interim multipliers for lags one through four are just 0.25 times the coefficient on the monthly average price. The high level of autocorrelation in fuel prices makes estimation of the lagged parameters difficult without imposing structure on the lagged response. We experimented with several weighting schemes, each of which produced qualitatively similar results.
} 
average prices is 0.251 and statistically significant. These results are consistent with the previous specifications which attempt to estimate the short-run and longer-run responses independently. Furthermore, the estimates support the hypothesis that immediately after a fuel price increase drivers substitute away from driving. Similarly, response to average prices is consistent with carpool formation responding to earlier fuel price increases. The combined effect of the two price elasticities suggests on overall long-run response in HOV lanes of approximately 0.16. Turning to the mainline lanes on highways with HOV lanes, the estimated short-run elasticity is -0.048 . The coefficient on monthly average prices is -0.028 and is statistically significant at the one percent level. Notice that the response is different compared with mainline lanes on highways without HOV lanes where monthly average prices have no statistically significant relationship with traffic flows. Furthermore, taking the distributed lag interpretation of the model 5 results suggests a long-run effect of -0.076 which is consistent with the base model.

One interpretation of the results in Table 5 is that the aggregate HOV response consists of two parts. In the short-run, fuel price increases cause some carpool drivers to choose the alternative option resulting in a decrease in flow. This is consistent with the findings in models 3,4 and 5 . However in the longer-run, commuters are able to form carpools, resulting in an increase in HOV

lane flow. This effect is large enough such that the net effect is positive consistent with models 1 , 2 and 5.

For mainline lanes, the estimated elasticities are fairly similar across the specifications in Table 5 and are consistent with a short-run effect of drivers choosing the alternative option when fuel prices increase. Model 5 provides some evidence that time is also a factor in the flow response in mainline lanes on highways with HOV lanes. Our estimates suggest ML_HV flows also respond to longer-run trends captured by monthly average prices. This would be expected if these drivers are forming carpools and contributing to the observed increase in HOV lane flows. We find no evidence of similar behavior in mainline lanes on highways without HOV lanes.

\subsection{Station-level heterogeneity}

We investigate heterogeneity in the response to higher fuel prices by estimating station-level elasticities for each of the stations in our sample. We do this in two ways. First, assuming common year effects and weekly flow patterns, we estimate station-level elasticities by interacting a dummy for each station with fuel prices and report the coefficient on the interaction term. Second, we allow stations to have unique weekly flow patterns. To do this we first de-mean the data to allow for common year effects then estimate a separate OLS regression for each station. Figure 2 and Figure 
3 plot the distributions of station flow elasticities by lane type. We see that there is substantial variability in the flow response at any individual station. However, the station-level results support the findings in the previous section. For both ML and ML_HOV lanes the masses of the probability distributions lie mainly to the left of zero with means 0.00 to -0.02 for mainline lanes and -0.03 to -0.04 for mainline lanes on highways with an HOV lane. For HOV lanes, the masses of the probability distributions lie to the right of zero with mean values between 0.09 and 0.15 .

Section 2.3 suggests that factors such as the length of commute, income or access to public transit may impact drivers' responses to changing fuel prices. Given the substantial heterogeneity we observe in the station-level estimates, we are interested in determining whether observable factors explain some of the variation in flow elasticities or whether these difference are more likely due to unobservable characteristics of drivers and the highway network. As motivation for the empirical exercise that follows, Figure 4 plots the estimated station-level flow elasticity versus the route-distance from downtown Los Angeles for HOV lanes on I-210 and mainline lanes on I-101. The results for HOV lanes on I-210 suggest a larger positive response to changing gas prices further from downtown. This is consistent with longer commute distances and greater average gasoline expenditure per trip resulting in more elastic carpool behavior. For mainline lanes on I-101 we see different behavior. In particular the flow response to changing fuel prices becomes less elastic further from downtown. One possible explanation is that because incomes rise substantially in the suburbs, the magnitude of the flow response falls with income. ${ }^{38}$ To illustrate this, we also plot median household income for the zip code where each station is located. The income curve increases the greater the distance from downtown.

We investigate more formally the potential sources of heterogeneity in the response to fuel price changes by correlating our station level elasticity estimates with observable characteristics of neighborhoods around each station. While an imperfect measure of driver characteristics, we believe observables near each station are likely correlated with the characteristics of drivers who use this section of highway. We focus on elasticity estimates from the specification assuming common year and week effects. Section 2 suggests the price response should depend on the characteristics of commuters, namely, fuel expenditures $g$, the value of time $\omega$, variable costs of the alternative option $\gamma$, and carpool formation $\operatorname{costs} \tau$. We construct proxies for each of these variables using geographic data and the 2000 Census.

We match zip-code level data to each station based on its location in Los Angeles. We approximate fuel expenditure $g$ using each station's distance from downtown Los Angeles. Specifically,

\footnotetext{
${ }^{38}$ For example due to gasoline representing a smaller share of household consumption.
} 
distance from "downtown" is the route distance from each station to the station on the same freeway closest to Union Station. In doing so we assume individual fuel economy and commute destinations are orthogonal to the flow elasticity. We use median household personal income as a proxy for the mean value of time $\omega$ in a neighborhood. For the alternative option $\gamma$ we use the fraction of worker trips made by public transit which should be correlated with the public transit infrastructure in a given neighborhood. Finally, we use population density measured in persons per square mile as a measure of the implied transaction costs of carpool formation.

Table 6 presents the results of models which regress the estimated flow elasticities on the above neighborhood characteristics. Model 1 includes only the distance variables interacted with indicators for lane type. The estimates for elasticities in HOV lanes and mainline lanes on highways without HOV lanes are positive and statistically significant. Moving one mile away from downtown is associated with a 0.003 increase in the price elasticity for mainline lanes on highways without an HOV lane. In other words because the mean elasticity is negative, flow is less elastic further from downtown. For HOV lanes, moving one mile further from downtown is associated with a 0.007 increase in the flow elasticity, i.e. HOV lane flow is more elastic further from downtown. Model 2 adds the natural log of median household income interacted with station type. None of the income parameters are statistically significant. The distance effect for mainline lanes is no longer statistically significant, though in HOV lanes the effect is similar to model 1 and significant. Model 3 adds the full set of neighborhood characteristics. The effect of distance on the flow response in HOV lanes is unchanged. Income appears to have a negative relationship with flow elasticity in carpool lanes suggesting that commuters from wealthy areas are less likely to form carpools when fuel prices rise. In model 3, population density appears to have a negative and statistically significant effect on HOV lane flow elasticity. The interpretation of this estimate is unclear, but suggests commuters from more densely populated areas may be more likely to choose the alternative option when fuel prices rise.

In looking at the estimated elasticities, we would be remiss not to mention that HOV stations on route I-210 show a particularly strong relationship between the flow response and distance from downtown. Models 4 drops observations from I-210 from the sample. We see that when these observations are excluded, the relationships between HOV flow elasticities, route distance and income are no longer statistically significant. However, we note that the signs of the estimates are consistent with estimates including I-210 stations.

Our interpretation of the results in Table 6 is that the observable characteristics of Los Angeles freeways and drivers do not seem to have a large impact on the response of traffic flows to fuel price changes. We note that none of the models in Table 6 explain more than 9 percent of the vari- 
ation in flow elasticities. Modeling individual driver behavior in this context is quite complicated. Commuters may have several highways from which to choose on a particular trip. In equilibrium, they may choose the least congested route. However, because of bottlenecks, merges or other local conditions, fuel price changes are likely to affect congestion differently along different routes. Modeling driver route choice and the interaction between fuel price changes and local traffic congestion is well beyond the scope of this paper. However, Table 6 is helpful in elucidating some trends in the responses of drivers, in particular that income and commute distance may be important factors affecting carpool formation. We view this as an important area for future research.

\section{Conclusions}

Understanding how commuters respond to changes in fuel prices, whether they form carpools, and how this behavior differs if HOV lanes are present has important implications for any policy that affects fuel prices. We show that on average, flows in high occupancy vehicle (HOV) lanes increase in response to higher fuel prices, while flows in mainline lanes decrease. Our preferred elasticity estimates are 0.136 for HOV lanes and -0.083 and -0.050 for highways with and without an HOV lane. While our theoretical model predicts the net effect of higher prices on carpooling could positive or negative, our empirical results suggest higher prices increases the number of carpools. The fact that more of these commuters choose to carpool instead of the alternative option implies preferences for driving are strong enough to prevent many commuters from opting out of driving entirely when fuel prices rise.

We also find that mainline flows are more responsive to fuel prices when an HOV lane is present. Because the locations of HOV lanes in our sample were not randomly assigned we cannot necessarily conclude that this relationship is causal. ${ }^{39}$ However, we do take this as suggestive evidence that fuel price increases could have a larger reduction in the social costs of driving for cities with better HOV lane infrastructure. To understand whether the higher elasticity leads to fewer total vehicles on the road, consider the effects for each highway configuration. For highways without an HOV lane, higher prices result in some commuters choosing the alternative option, which reduces the number of vehicles on the road. For highways with an HOV lane, higher prices result in some commuters choosing the alternative option, while some choose to carpool. Intuitively, the decrease in mainline drivers may be offset by an increase in HOV lane use. Therefore, the net effect on

\footnotetext{
${ }^{39}$ For example, one might worry that HOV lanes were preferentially located on major commuting routes where drivers have systematically different preferences for driving or public transportation.
} 
the number of vehicles on the road depends on the initial number of drivers in each lane and the configuration of each highway.

We investigate the overall response to fuel price change in Los Angles by performing the following back of the envelop calculation. Using the estimated flow elasticities from Table 3 model 3, we calculate the total change in hourly flow for representative highways with and without an HOV lane. For simplicity we assume a $10 \%$ increase in fuel prices and use the sample mean flows and configurations for each highway type. ${ }^{40}$ Under these assumptions, we find that flow on the mainline only highway decreases by approximately 27 vehicles per hour. Flow in the mainline portion of the mainline highway with an HOV lane decreases by approximately 45 vehicles per hour and flow in the HOV lane increases by approximately 10 vehicles per hour. Therefore, the net effect is a greater decrease in the number of vehicles per hour when the HOV lane is present. ${ }^{41}$ Furthermore, assuming each carpool consists of on average two commuters, we note that total number of drivers choosing the alternative option is comparable on both highways, 27 in the ML case and $45-(2 \times$ 10) $=25$ for ML_HV drivers.

While we do not estimate changes in vehicle related social costs directly, the fact the we estimate a net reduction in the number of vehicles on the road implies higher prices reduce external costs. For example, emissions of criteria pollutants from motor vehicles are generally thought to be proportional to miles driven (Parry, Walls, and Harrington (2007)). ${ }^{42}$ A larger total response to fuel price increases implies a greater reduction in emissions. Similar effects are likely to hold for traffic congestion, accidents and other driving-related social costs.

In the spirit of Verhoef, Nijkamp, and Rietveld (1996) we should not forget that the building of HOV lanes is likely a second-best approach to congestion relief absent optimal congestion tolls. Furthermore, the possibility that HOV lanes may result in a larger decrease in vehicle-related externalities due to short-run fuel price changes does not imply that building HOV lanes is an optimal policy. Determining whether or not additional HOV lanes are socially optimal would require a more comprehensive analysis, incorporating long-run considerations such as those in Duranton and Turner (2011). Recent research has examined converting existing HOV lanes into HOT (high-occupancy toll) lanes, with Small, Winston, and Yan (2006) finding that HOT lanes are welfare improving over HOV lanes. If HOT tolls are set equal to the marginal social cost of an additional vehicle, our estimates suggest that if gas prices increased by $10 \%$, the optimal toll would

\footnotetext{
${ }^{40}$ Specifically, mean hourly flows per lane of 1326, 1345 and 706 for ML, ML_HV and HOV lanes and 4-lane mainline highways and 5 lane ML_HV highways including one HOV lane.

${ }^{41}$ We note that in this example the HOV highway has one additional lane.

${ }^{42}$ This is because automakers are held to emissions standards that stipulate grams per mile emissions rates.
} 
rise by 1.3 cents/mile due to increased carpooling behavior under reasonable assumptions. ${ }^{43}$

In summary, we document three effects related to fuel prices, carpooling and the social costs of driving. First, higher fuel prices lead to fewer drivers in mainline lanes. Second, higher prices lead to an increase in carpooling on highways with HOV lanes. Third, the total reduction in the number of vehicles on the road is greater on highways with an HOV lane. Based on our model in Section 2 this last result implies the presence of an HOV lane provides a better substitute to the outside option when commuters are faced with higher prices. As a result, commuters who would have continued driving alone absent an HOV option instead choose to carpool. Finally, for both highways with and without HOV lanes we show that higher prices on average reduce the number of vehicles on the road. These effects have important implications for any policy that results in changes in fuel prices.

\footnotetext{
${ }^{43}$ Specifically, we assume that changes in travel time are proportional to changes in flow, average speeds of $45 \mathrm{mph}$, carpool occupancy of 2 , and a value of time of $\$ 21.46$ (Small, Winston, and Yan, 2005)
} 


\section{References}

Barth, M. and K. Boriboonsomsin. 2008. "Real-world carbon dioxide impacts of traffic congestion." Transportation Research Record: Journal of the Transportation Research Board 2058 (-1):163171.

Blanchard, Christopher. 2009. "The Impact of Rising Gasoline Prices on U.S. Public Transit Ridership." Duke University, mimeo .

Burger, N.E. and D.T. Kaffine. 2009. "Gas prices, traffic, and freeway speeds in Los Angeles." The Review of Economics and Statistics 91 (3):652-657.

Busse, M.R., C.R. Knittel, and F. Zettelmeyer. 2010. "Pain at the pump: The effect of gasoline prices on new and used automobile markets." NBER Working Paper 15590.

Currie, Graham and Justin Phung. 2007. "Transit Ridership Auto Gas Prices, and World Events: New Drivers of Change?" Transportation Research Record: Journal of the Transportation Research Board $1992(2): 3-10$.

Dahl, C. and T. Sterner. 1991. "Analysing gasoline demand elasticities: a survey." Energy Economics 13 (3):203-210.

Davis, L.W. and L. Kilian. 2011. "Estimating the effect of a gasoline tax on carbon emissions." Journal of Applied Econometrics 26 (7):1187-1214.

Duranton, Gilles and Matthew A. Turner. 2011. "The Fundamental Law of Road Congestion: Evidence from US Cities." American Economic Review 101 (6):261652.

Elliott, Graham, Thomas J. Rothenberg, and James H. Stock. 1996. "Efficient Tests for an Autoregressive Unit Root." Econometrica 64 (4):813-836.

Espey, M. 1998. "Gasoline demand revisited: an international meta-analysis of elasticities." Energy Economics 20 (3):273-295.

Giuliano, G., D.W. Levine, and R.F. Teal. 1990. "Impact of high occupancy vehicle lanes on carpooling behavior." Transportation 17 (2):159-177.

Grabowski, David C. and Michael A. Morrisey. 2006. "Do Higher Gasoline Taxes Save Lives?" Economic Letters 90:51-55.

Hughes, Jonathan E., Christopher R. Knittel, and Daniel Sperling. 2008. "Evidence of a Shift in the Short-Run Price Elasticity of Gasoline Demand." Energy Journal 29 (1):113-134. 
Im, Kyung So, M.Hashem Pesaran, and Yongcheol Shin. 2003. "Testing for unit roots in heterogeneous panels." Journal of Econometrics 115 (1):53 - 74.

Johnston, R.A. and R. Ceerla. 1996. "The effects of new high-occupancy vehicle lanes on travel and emissions." Transportation Research Part A: Policy and Practice 30 (1):35-50.

Klier, Thomas and Joshua Linn. 2010. "The Price of Gasoline and New Vehicle Fuel Economy: Evidence from Monthly Sales Data." American Economic Journal: Economic Policy 2 (3):134153.

Knittel, Christopher R. and Ryan Sandler. 2011. "Cleaning the Baby with the Bathwater: The Health Co-Benefits of Carbon Pricing in Transportation." NBER Working Paper No. 17390 .

Kwon, J. and P. Varaiya. 2008. "Effectiveness of Californias high occupancy vehicle (HOV) system." Transportation Research Part C: Emerging Technologies 16 (1):98-115.

Lee, L.W. 1984. "The economics of carpools." Economic Inquiry 22 (1):128-135.

Levin, Andrew, Chien-Fu Lin, and Chia-Shang James Chu. 2002. "Unit root tests in panel data: asymptotic and finite-sample properties." Journal of Econometrics 108 (1):1 - 24.

Li, Shanjun, Christopher Timmins, and Roger H von Haefen. 2010. "How do Gasoline Prices Affect Fleet Fuel Economy." American Economic Journal: Economic Policy 1 (2):113-137.

Maddala, G. S. and Shaowen Wu. 1999. "A Comparative Study of Unit Root Tests with Panel Data and a New Simple Test." Oxford Bulletin of Economics and Statistics 61 (S1):631-652.

Parry, I.W.H. and A. Bento. 2001. "Revenue recycling and the welfare effects of road pricing." The Scandinavian Journal of Economics 103 (4):645-671.

Parry, I.W.H. and K.A. Small. 2005. "Does Britain or the United States have the right gasoline tax?" The American Economic Review 95 (4):1276-1289.

Parry, I.W.H., M. Walls, and W. Harrington. 2007. "Automobile Externalities and Policies." Journal of Economic Literature 45 (2):373-399.

Puller, Steven L. and Lorna A. Greening. 1999. "Household Adjustment to Gasoline Price Change: An Analysis Using 9 Years of US Survey Data.” Energy Economics 21 (1):37-52.

Rodier, C.J. and R.A. Johnston. 1997. "Travel, emissions, and welfare effects of travel demand management measures." Transportation Research Record: Journal of the Transportation Research Board 1598 (-1):18-24. 
Shewmake, Sharon. 2010. "Can carpooling clean the air? The economics of HOV lanes, hybrid cars and the Clean Air Act." MPRA Paper 26129, University Library of Munich, Germany. URL http://ideas.repec.org/p/pra/mprapa/26129.html.

Small, Kenneth A., Clifford Winston, and Jia Yan. 2005. "Uncovering the Distribution of Motorists' Preferences for Travel Time and Reliability." Econometrica 73 (4):1367-1382.

- 2006. "Differentiated Road Pricing, Express Lanes, and Carpools: Exploiting Heterogeneous Preferences in Policy Design." Brookings-Wharton Papers on Urban Affairs :pp. 53-96.

Verhoef, Erik, Peter Nijkamp, and Piet Rietveld. 1996. "Second-Best Congestion Pricing: The Case of an Untolled Alternative." Journal of Urban Economics 40 (3):279 - 302. 


\section{$7 \quad$ Figures}

Figure 1: Total weekly flow during weekday peak hours and fuel prices for mainline lanes, mainline lanes on freeways with an HOV lane, and HOV lanes.

(a) Mainline lanes

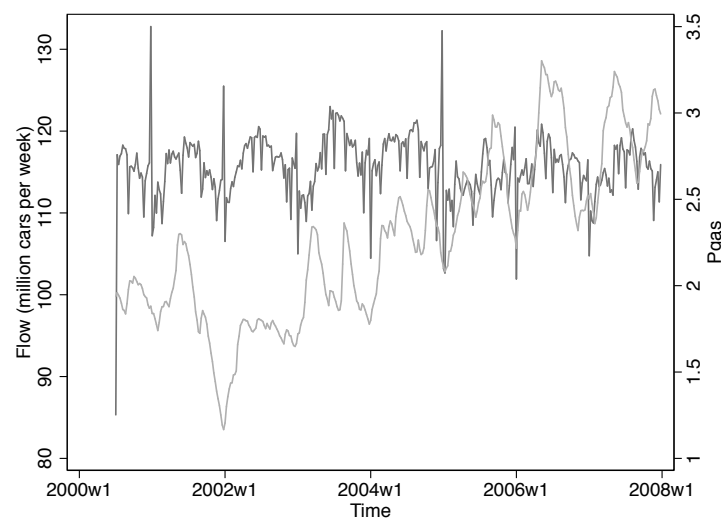

(b) Mainline lanes with $\mathrm{HOV}$

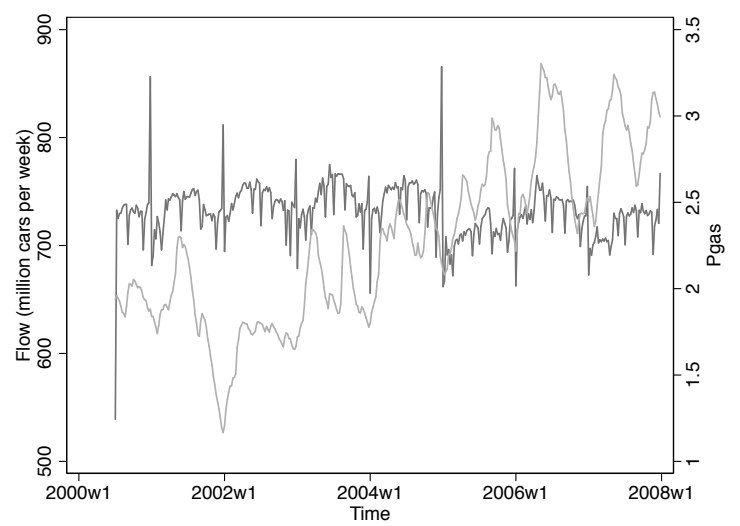

(c) HOV lanes

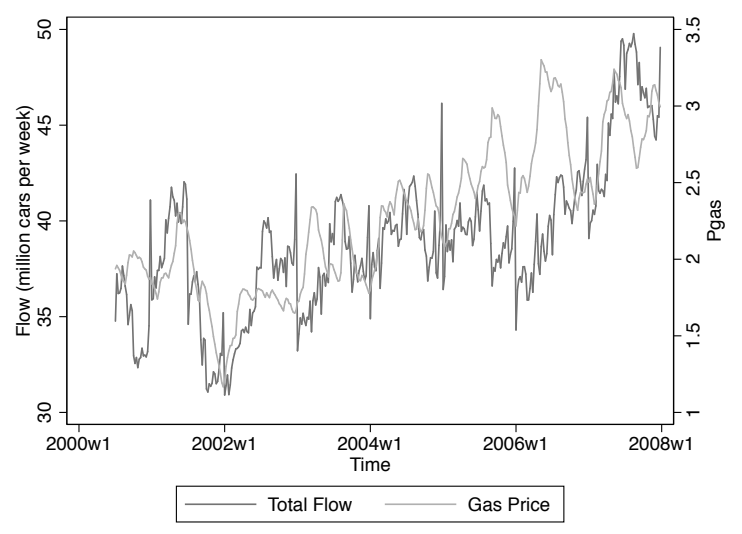


Figure 2: Distributions of station-level elasticities by lane type assuming common year and week mean-effects across stations. The distributions are truncated to include estimates between -1 and 1.

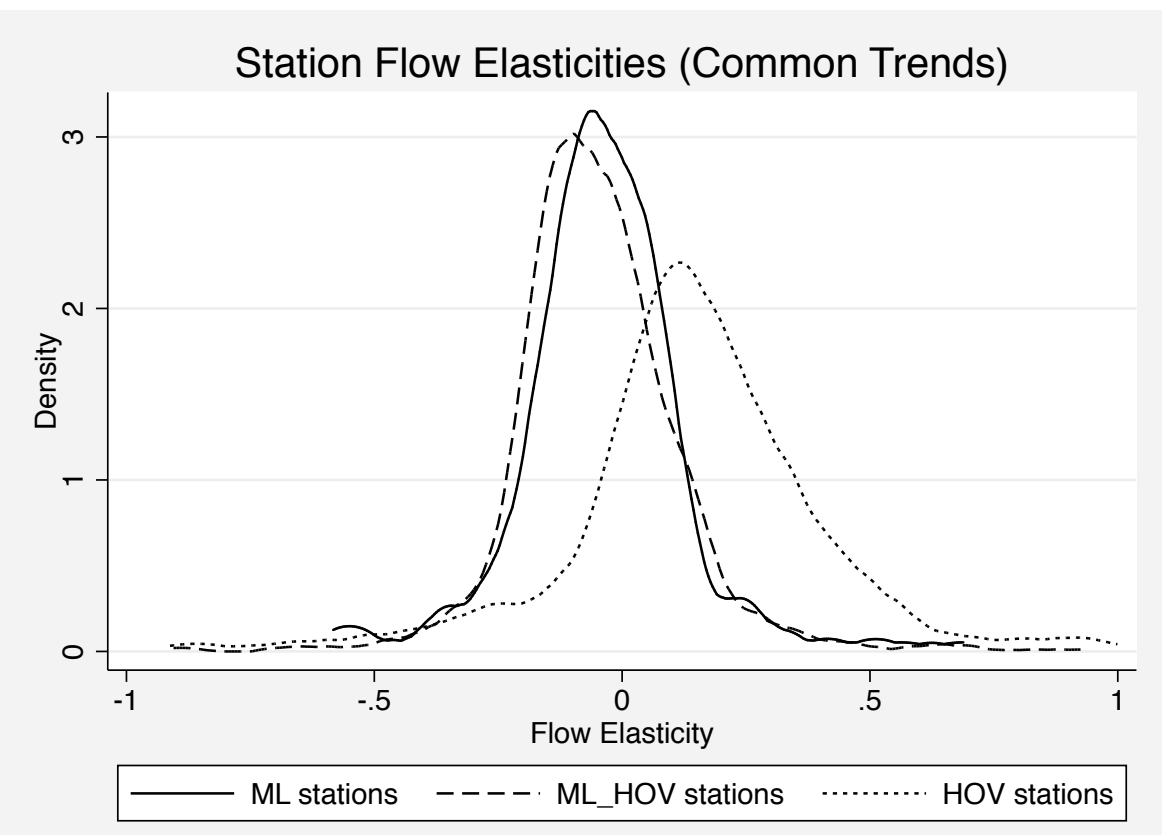

Figure 3: Distributions of station-level elasticities by lane type accounting for station-specific week mean-effects. The distributions are truncated to include estimates between -1 and 1 .

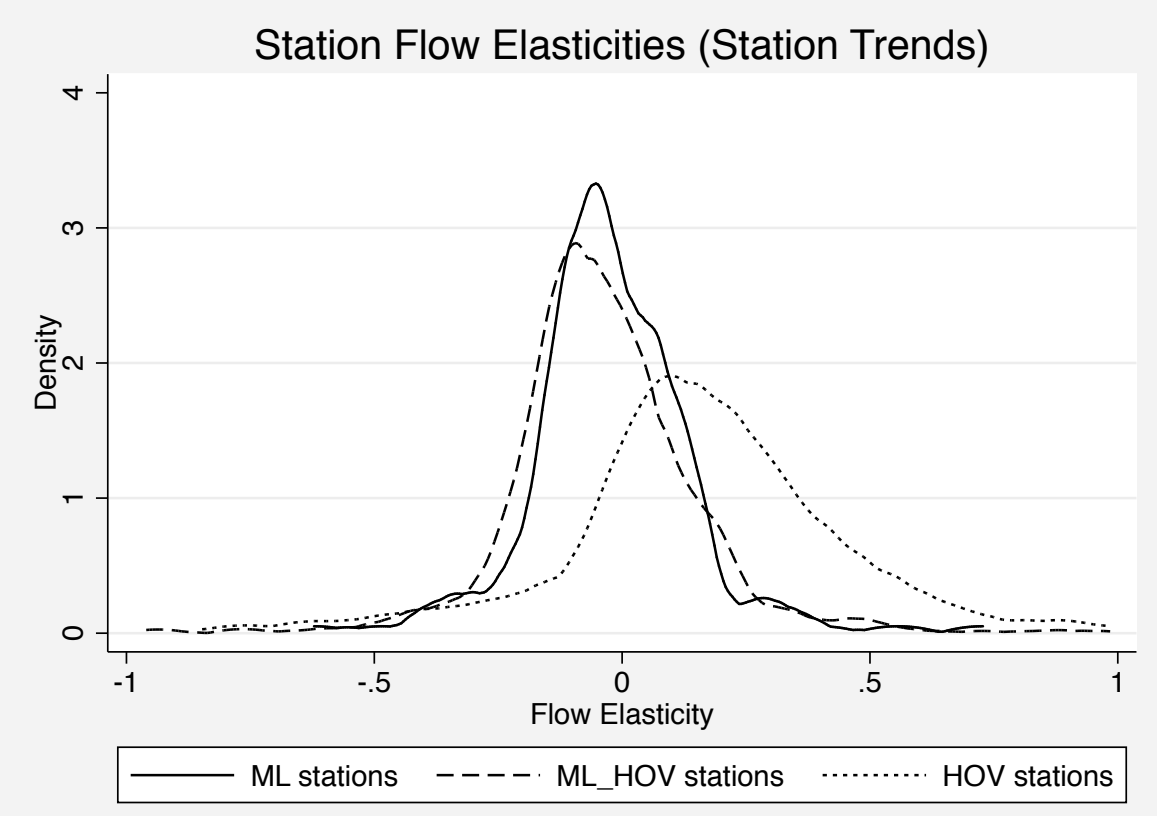


Figure 4: Station-level elasticity estimates versus distance from downtown Los Angeles. The smoothed lines are created using a weighted locally linear least squares procedure.

(a) I-210 HOV Lanes

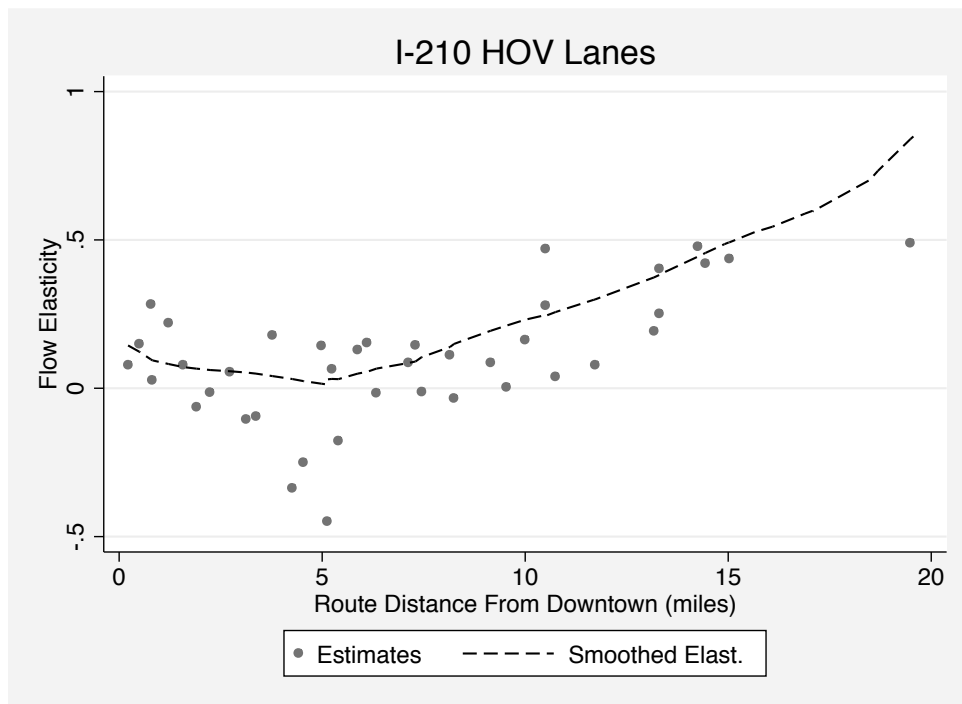

(b) I-101 Mainline Lanes

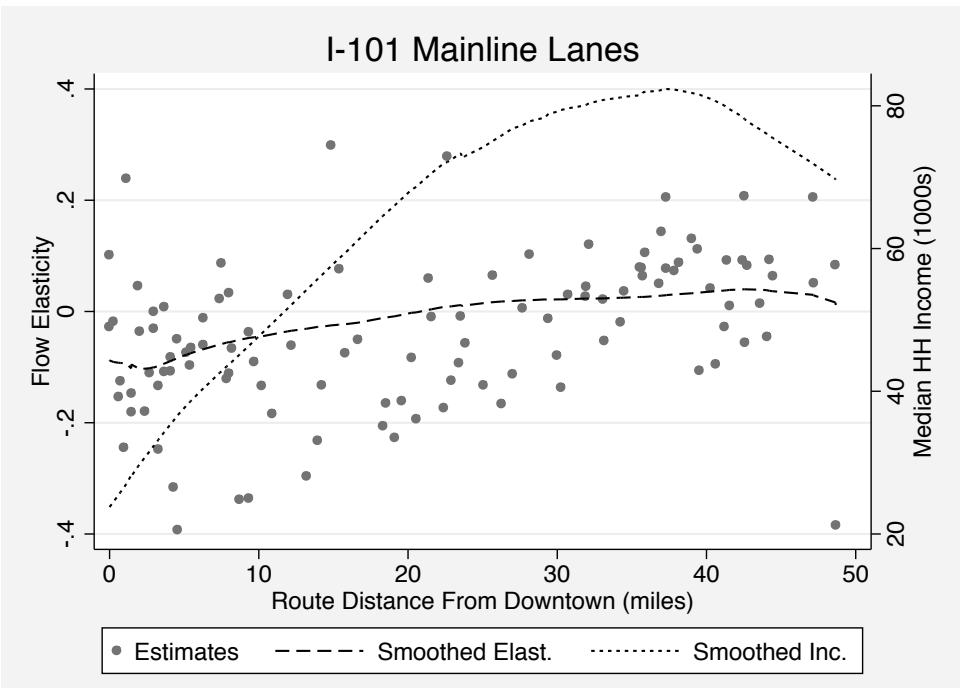




\section{Tables}

Table 1: Analytical results across scenarios and cases

\begin{tabular}{ccccccc}
\hline \hline & & Case A & & & Case B & \\
& Route & Price Effect & Sign & Route & Price Effect & Sign \\
\hline \multirow{2}{*}{ Scenario 1 } & ML & $-\frac{g L}{w \alpha}$ & - & ML & $-\frac{g L}{w \alpha+\gamma L}$ & - \\
& Alt & $\frac{g L}{w \alpha}$ & + & Alt & $\frac{g L}{w \alpha+\gamma L}$ & + \\
\hline \multirow{5}{*}{ Scenario 2 } & HOV & $-\frac{g}{2 w \alpha}$ & - & HOV & $-\frac{g(w \alpha+(1-L) \gamma)}{2 w \alpha(w \alpha+(1+L) \gamma)}$ & $+/-$ \\
& ML & $-\frac{g(L-1)}{w \alpha}$ & - & ML & $-\frac{g(L-1)(w \alpha+\gamma)}{w \alpha(w \alpha+(1+L) \gamma)}$ & - \\
& Alt & $\frac{g L}{w \alpha}$ & + & Alt & $\frac{g L}{w \alpha+(1+L) \gamma}$ & + \\
\hline
\end{tabular}

Note: Scenario 1 represents a configuration of $L$ mainline lanes and an alternative option. Scenario

2 consists of a configuration of $L-1$ mainline lanes, one HOV lane, and an alternative option. Case A corresponds to constant cost of the alternative option across commuters. Case B corresponds

to heterogeneous costs of the alternative option across commuters. 
Table 2: Summary statistics for weekday peak, weekday off-peak and weekend periods.

\begin{tabular}{|c|c|c|c|c|c|}
\hline & Num. Obs. & Mean & Std. Dev. & Min. & Max. \\
\hline \multicolumn{6}{|l|}{ Weekday Peak } \\
\hline flow (veh.) & 673,530 & 309,026 & 175,640 & 0 & $1,000,000$ \\
\hline $\ln ($ flow $)$ & 673,530 & 12.33 & 0.94 & 8.74 & 13.86 \\
\hline mean hourly flow (veh./lane-hr.) & 673,530 & 1,150 & 368 & 0 & 4,112 \\
\hline price gasoline $(\$ 2005)$ & 673,530 & 2.26 & 0.48 & 1.17 & 3.30 \\
\hline $\ln ($ price gasoline $)$ & 673,530 & 0.79 & 0.21 & 0.15 & 1.19 \\
\hline number lanes & 673,530 & 3.29 & 1.46 & 1.00 & 7.00 \\
\hline \multicolumn{6}{|l|}{ Weekday Off-Peak } \\
\hline flow (veh.) & 673,530 & 69,163 & 45,801 & 0 & 582,655 \\
\hline $\ln ($ flow $)$ & 673,530 & 10.61 & 1.34 & 3.00 & 13.28 \\
\hline mean hourly flow (veh./lane-hr.) & 673,530 & 403 & 218 & 0 & 4,316 \\
\hline price gasoline $(\$ 2005)$ & 673,530 & 2.26 & 0.48 & 1.17 & 3.30 \\
\hline In(price gasoline) & 673,530 & 0.79 & 0.21 & 0.15 & 1.19 \\
\hline number lanes & 673,530 & 3.29 & 1.46 & 1.00 & 7.00 \\
\hline \multicolumn{6}{|l|}{ Weekend Peak } \\
\hline flow (veh.) & 673,530 & 106,749 & 61,898 & 0 & 515,274 \\
\hline $\ln ($ flow $)$ & 673,530 & 11.27 & 0.94 & 6.78 & 13.15 \\
\hline mean hourly flow (veh./lane-hr.) & 673,530 & 999 & 339 & 0 & 4,100 \\
\hline price gasoline $(\$ 2005)$ & 673,530 & 2.26 & 0.48 & 1.17 & 3.30 \\
\hline $\ln$ (price gasoline) & 673,530 & 0.79 & 0.21 & 0.15 & 1.19 \\
\hline number lanes & 673,530 & 3.29 & 1.46 & 1.00 & 7.00 \\
\hline \multicolumn{6}{|l|}{ Weekend Off-Peak } \\
\hline flow (veh.) & 673,530 & 28,210 & 19,128 & 0 & 276,407 \\
\hline $\ln ($ flow $)$ & 673,530 & 9.75 & 1.28 & 1.10 & 12.53 \\
\hline mean hourly flow (veh./lane-hr.) & 673,530 & 415 & 224 & 0 & 5,119 \\
\hline price gasoline (\$2005) & 673,530 & 2.26 & 0.48 & 1.17 & 3.30 \\
\hline In(price gasoline) & 673,530 & 0.79 & 0.21 & 0.15 & 1.19 \\
\hline number lanes & 673,530 & 3.29 & 1.46 & 1.00 & 7.00 \\
\hline
\end{tabular}




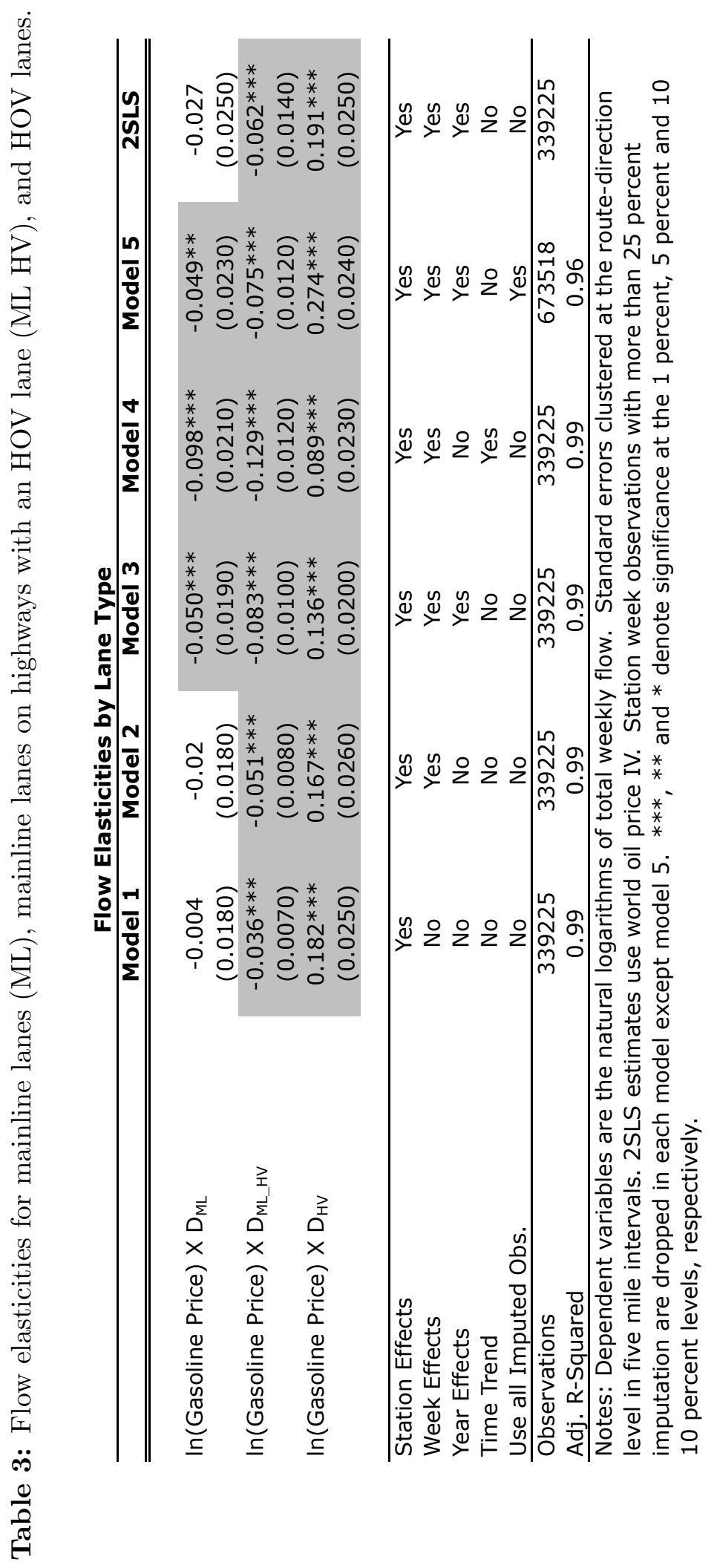




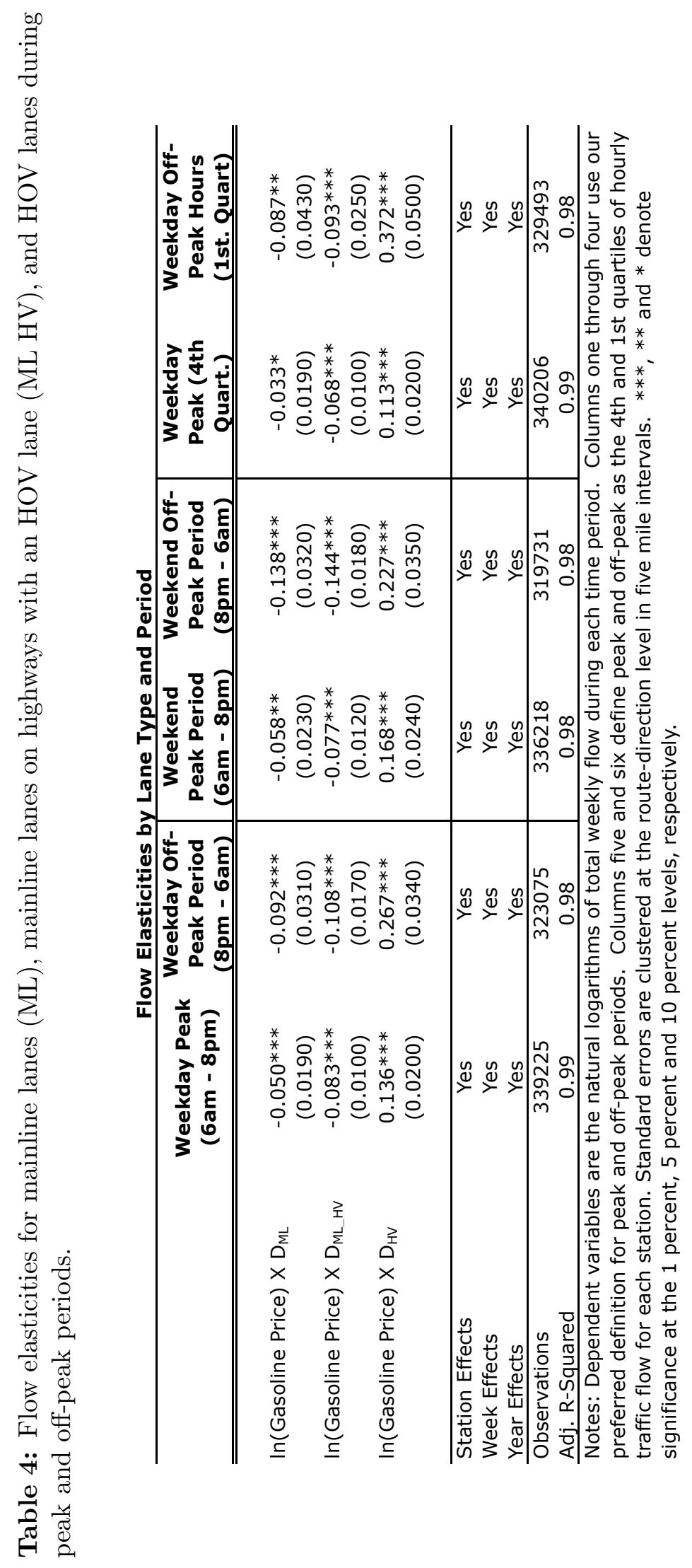




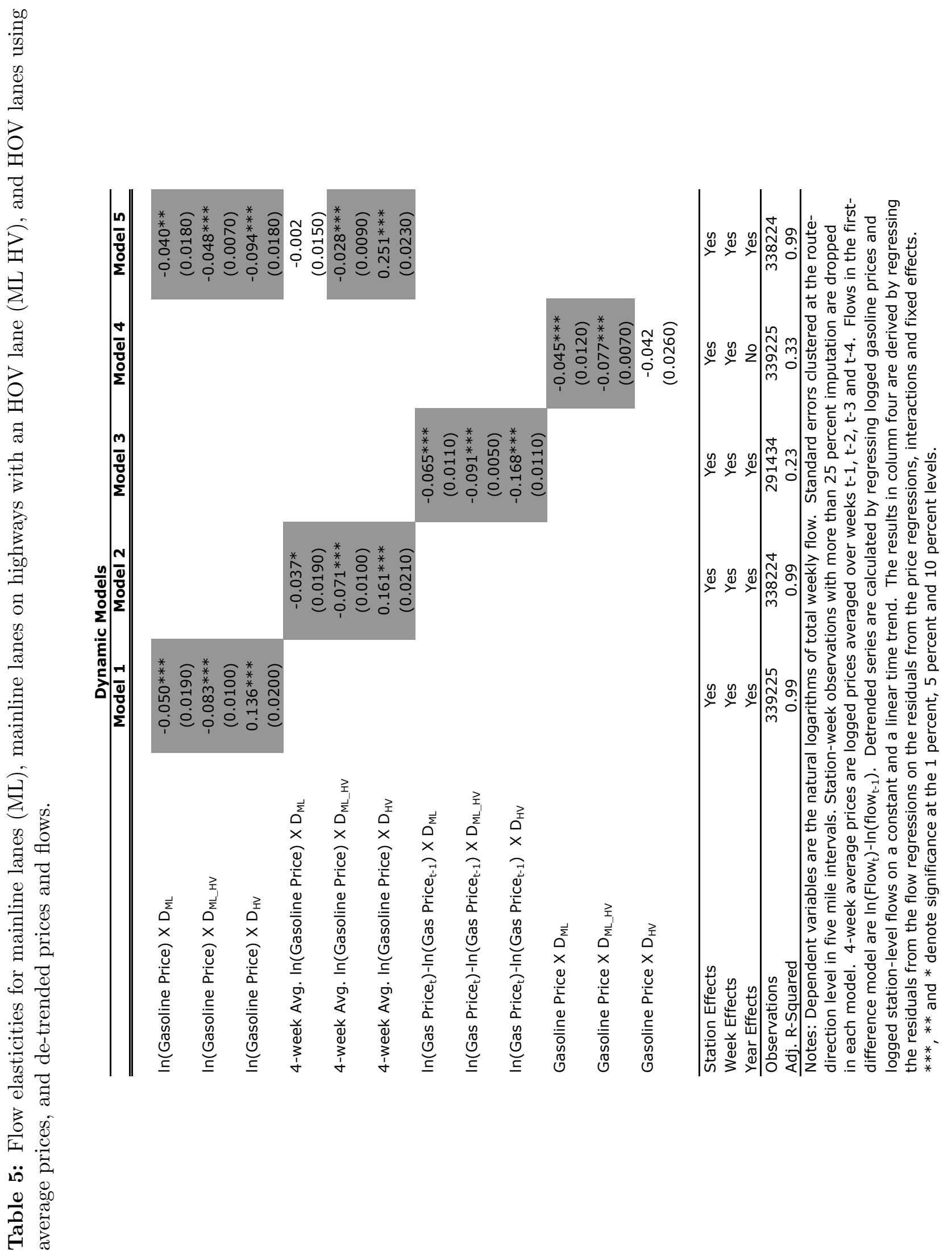


Table 6: Correlations between station-level elasticity estimates and observable neighborhood characteristics.

\begin{tabular}{|c|c|c|c|c|}
\hline & Model 1 & Model 2 & Model 3 & Model 4 \\
\hline Route Distance $X \mathrm{D}_{\mathrm{ML}}$ & $\begin{array}{c}0.003^{*} \\
(0.0020)\end{array}$ & $\begin{array}{c}0.001 \\
(0.0030)\end{array}$ & $\begin{array}{c}0.002 \\
(0.0030)\end{array}$ & $\begin{array}{c}0.019 \\
(0.0180)\end{array}$ \\
\hline Route Distance X D $\mathrm{ML}_{\mathrm{HV}}$ & $\begin{array}{c}0.001 \\
(0.0010)\end{array}$ & $\begin{array}{c}0.002 \\
(0.0020)\end{array}$ & $\begin{array}{c}0.002 \\
(0.0020)\end{array}$ & $\begin{array}{c}0.000 \\
(0.0020)\end{array}$ \\
\hline Route Distance X $D_{\mathrm{HV}}$ & $\begin{array}{c}0.007 * * \\
(0.0030)\end{array}$ & $\begin{array}{c}0.007 * * \\
(0.0030)\end{array}$ & $\begin{array}{l}0.007 * * \\
(0.0030)\end{array}$ & $\begin{array}{c}0.001 \\
(0.0030)\end{array}$ \\
\hline $\ln (\mathrm{HH}$ Income $) \times D_{M L}$ & & $\begin{array}{c}0.100 \\
(0.0980)\end{array}$ & $\begin{array}{c}0.163 \\
(0.1850)\end{array}$ & $\begin{array}{c}0.662 \\
(0.5310)\end{array}$ \\
\hline In(HH Income $) \times D_{M L} H_{V}$ & & $\begin{array}{c}-0.045 \\
(0.0370)\end{array}$ & $\begin{array}{c}-0.003 \\
(0.0530)\end{array}$ & $\begin{array}{c}0.003 \\
(0.0530)\end{array}$ \\
\hline $\ln (\mathrm{HH}$ Income $) \times D_{H V}$ & & $\begin{array}{c}-0.033 \\
(0.0550)\end{array}$ & $\begin{array}{c}-0.206 * * \\
(0.0940)\end{array}$ & $\begin{array}{c}-0.11 \\
(0.0970)\end{array}$ \\
\hline $\ln$ (Pop. Density) $\times D_{M L}$ & & & $\begin{array}{c}0.059 \\
(0.0480)\end{array}$ & $\begin{array}{c}-0.05 \\
(0.1070)\end{array}$ \\
\hline In(Pop. Density) X D $D_{M L \_H V}$ & & & $\begin{array}{c}0.004 \\
(0.0190)\end{array}$ & $\begin{array}{c}-0.003 \\
(0.0190)\end{array}$ \\
\hline In(Pop. Density) X $D_{\mathrm{HV}}$ & & & $\begin{array}{c}-0.138 * * * \\
(0.0350)\end{array}$ & $\begin{array}{c}-0.112 * * * \\
(0.0360)\end{array}$ \\
\hline Transit Mode Share $X D_{M L}$ & & & $\begin{array}{c}-0.27 \\
(0.7720)\end{array}$ & $\begin{array}{c}3.272 \\
(3.3980)\end{array}$ \\
\hline Transit Mode Share X $D_{M L \_H V}$ & & & $\begin{array}{c}0.194 \\
(0.2860)\end{array}$ & $\begin{array}{c}0.172 \\
(0.2780)\end{array}$ \\
\hline Transit Mode Share $X D_{H V}$ & & & $\begin{array}{c}0.003 \\
(0.5590)\end{array}$ & $\begin{array}{c}0.168 \\
(0.5490)\end{array}$ \\
\hline Lane Type Effects & Yes & Yes & Yes & Yes \\
\hline Route Effects & Yes & Yes & Yes & Yes \\
\hline Include I-210 Stations & Yes & Yes & Yes & No \\
\hline Observations & 1651 & 1651 & 1651 & 1421 \\
\hline Adj. R-Squared & 0.08 & 0.08 & 0.09 & 0.08 \\
\hline
\end{tabular}




\section{A Appendix}

\section{Appendices}

\section{A.1 Extension of Parry and Bento (2001)}

While the equilibrium sorting model presented in the main text provides intuition for the empirical results, here we develop a formal household choice model grounded in microeconomic theory. We begin by extending Parry and Bento (2001) to consider a representative household who makes a labor/leisure decision and a commute decision between driving (either in the HOV lane or alone in the mainline) and an alternative transportation option (i.e. public transit). We are ultimately interested in how the commute choice varies with the price of gasoline. Household utility is given by:

$$
U=u(C, N)+T(D, A)
$$

where we will assume $u$ is concave and $T$ is strictly concave $\left(u_{C C} \leq 0, u_{N N} \leq 0, T_{D D}<0, T_{A A}<\right.$ $\left.0, T_{D A}<0\right) .{ }^{44} C$ is consumption of household goods, and $N$ is consumption of leisure. $D$ represents commutes taken by driving, which can be separated into HOV commutes $(H)$ and mainline commutes $(R)$, such that $D=H+R$, and $A$ represents commutes taken via the alternative option. The labor supply $(L)$ in this model is chosen by the household, such that total number of commutes is equal to the labor supply, such that:

$$
L=H+R+A .
$$

Households have an endowment of time $\bar{L}$ that can be allocated to working, leisure, or commuting. Commuting in the HOV lane costs households $\zeta+\tau$ amount of time, where $\zeta=\zeta(H)$ is the congestible travel time in the HOV lane and $\tau$ is the fixed transaction cost of carpool formation per commute. Commuting alone in the mainline lane costs households $\pi$ units of time where $\pi=\pi(R)$ is the congestible travel time in mainline lanes. While travel time in both the HOV lane and mainline lanes is congestible, each agent effectively takes the level of congestion as given (introducing

\footnotetext{
${ }^{44}$ Following Parry and Bento (2001), we assume that households receive (dis)utility from commuting, such that driving and alternative transportation are allowed to be imperfect substitutes. Furthermore, Equation 10 implies separability between labor/leisure decisions and the commuting choice.
} 
a congestion externality to other drivers). Finally, we assume that travel time in the alternative option is uncongestible and equal to $\phi$. Thus, the household time constraint is given by:

$$
\bar{L}=N+L+(\zeta(H)+\tau) H+\pi(R) R+\phi A .
$$

The household also faces a budget constraint. Normalizing labor and the consumption good, the budget constraint can be expressed as:

$$
L=C+\frac{p}{2} H+p R
$$

where labor supply is equal to consumption plus gasoline expenditure from commuting. $p$ represents the per commute price of gasoline, which is paid in full when commuting alone by $R$ but is shared when carpooling in the HOV lane $H$.

Thus, the household seeks to maximize (10) choosing consumption, leisure, labor supply, HOV commutes, mainline commutes, and alternative option commutes, taking into account (11), (12), and (13). It is convenient for our purposes to rearrange the constraints such that $C(H, R, A)=$ $H+R+A-\frac{p}{2} H-p R$ and $N=\bar{L}-H-R-A-(\zeta(H)+\tau) H-\pi(R) R-\phi A$. This allows us to express the maximization problem purely in terms of the commute choice:

$$
\max _{H, R, A} U=u(C(H, R, A), N(H, R, A))+T(D(H, R), A)
$$

which yields first-order conditions of:

$$
\begin{gathered}
U_{H}=U_{C} C_{H}+U_{N} N_{H}+T_{D} D_{H}=U_{C}\left(1-\frac{p}{2}\right)-U_{N}\left(1+\tau+\zeta+\zeta^{\prime} H\right)+T_{D}=0 \\
U_{R}=U_{C} C_{R}+U_{N} N_{R}+T_{D} D_{R}=U_{C}(1-p)-U_{N}\left(1+\pi+\pi^{\prime} R\right)+T_{D}=0 \\
U_{A}=U_{C} C_{A}+U_{N} N_{A}+T_{A}=U_{C}-U_{N}(1+\phi)+T_{A}=0
\end{gathered}
$$

By the concavity of the objective function, a maximum will be given by: $H^{\star}=H^{\star}(p, \zeta, \pi, \phi, \tau)$, $R^{\star}=R^{\star}(p, \zeta, \pi, \phi, \tau)$, and $A^{\star}=A^{\star}(p, \zeta, \pi, \phi, \tau)$. 
Determining the comparative statics of commute choice with respect to gas price requires an application of the implicit function theorem to the the first-order conditions $(15,16,17)$. Unfortunately, the general comparative statics are intractable to sign, thus we consider a special case of a concave utility function $u_{C, N}$ where $U_{C C}=U_{C N}=U_{N N}=0$. While we cannot show the more general case, we prove that for this specific case, the comparative statics yield results similar to those developed using the equilibrium sorting model. Totally differentiating the first-order conditions with respect to $H^{\star}, R^{\star}, A^{\star}$, and $p$ gives the following equations:

$$
\begin{gathered}
\left(T_{D D}-U_{N}\left(2 \zeta^{\prime}+\zeta^{\prime \prime} H\right)\right) d H^{\star}+T_{D D} d R^{\star}+T_{D A} d A^{\star}-\frac{U_{C}}{2} d p=0 \\
T_{D D} d H^{\star}+\left(T_{D D}-U_{N}\left(2 \pi^{\prime}+\pi^{\prime \prime} R\right)\right) d R^{\star}+T_{D A} d A^{\star}-U_{C} d p=0 \\
T_{D A} d H^{\star}+T_{D A} d R^{\star}+T_{A A} d A^{\star}=0
\end{gathered}
$$

which can be written as:

$$
\left[\begin{array}{ccc}
T_{D D}-U_{N}\left(2 \zeta^{\prime}+\zeta^{\prime \prime} H\right) & T_{D D} & T_{D A} \\
T_{D D} & T_{D D}-U_{N}\left(2 \pi^{\prime}+\pi^{\prime \prime} R\right) & T_{D A} \\
T_{D A} & T_{D A} & T_{A A}
\end{array}\right]\left[\begin{array}{c}
\frac{\partial H^{\star}}{\partial p} \\
\frac{\partial R^{\star}}{\partial p} \\
\frac{\partial A^{\star}}{\partial p}
\end{array}\right]=\left[\begin{array}{c}
\frac{U_{C}}{2} \\
U_{C} \\
0
\end{array}\right]
$$

Applying Cramer's rule yields the following comparative statics with respect to gas price $p$.

$$
\frac{\partial H^{\star}}{\partial p}=\frac{\frac{1}{2} U_{C}\left(T_{D A}^{2}-T_{D D} T_{A A}-T_{A A} U_{N}\left(2 \pi^{\prime}+\pi^{\prime \prime} R\right)\right)}{U_{N}\left(\left(T_{D A}^{2}-T_{D D} T_{A A}\right)\left(2 \pi^{\prime}+\pi^{\prime \prime} R\right)+\left(2 \zeta^{\prime}+\zeta^{\prime \prime} H\right)\left(T_{D A}^{2}-T_{D D} T_{A A}+T_{A A} U_{N}\left(2 \pi^{\prime}+\pi^{\prime \prime} R\right)\right)\right)}
$$

$$
\frac{\partial R^{\star}}{\partial p}=\frac{-\frac{1}{2} U_{C}\left(T_{D A}^{2}-T_{D D} T_{A A}+2 T_{A A} U_{N}\left(2 \pi^{\prime}+\pi^{\prime \prime} R\right)\right)}{U_{N}\left(\left(T_{D A}^{2}-T_{D D} T_{A A}\right)\left(2 \pi^{\prime}+\pi^{\prime \prime} R\right)+\left(2 \zeta^{\prime}+\zeta^{\prime \prime} H\right)\left(T_{D A}^{2}-T_{D D} T_{A A}+T_{A A} U_{N}\left(2 \pi^{\prime}+\pi^{\prime \prime} R\right)\right)\right)}
$$

$$
\frac{\partial A^{\star}}{\partial p}=\frac{\frac{1}{2} T_{D A} U_{C} U_{N}\left(2\left(2 \zeta^{\prime}+\zeta^{\prime \prime} H\right)+\left(2 \pi^{\prime}+\pi^{\prime \prime} R\right)\right)}{U_{N}\left(\left(T_{D A}^{2}-T_{D D} T_{A A}\right)\left(2 \pi^{\prime}+\pi^{\prime \prime} R\right)+\left(2 \zeta^{\prime}+\zeta^{\prime \prime} H\right)\left(T_{D A}^{2}-T_{D D} T_{A A}+T_{A A} U_{N}\left(2 \pi^{\prime}+\pi^{\prime \prime} R\right)\right)\right)}
$$


To sign these terms, we first note that the denominator of each expression is simply the Hessian, and for a maximum is thus strictly negative. Beginning with (24), we can unambiguously sign $\frac{\partial A^{\star}}{\partial p}>0$ as the numerator is strictly negative, implying that use of the alternative option increases as the price of gasoline increases. Next, because this solution represents a maximum, we know $T_{A A}\left(T_{D D}-U_{N} \pi^{\prime}\right)-T_{D A}^{2}>0$, which also implies $T_{A A}\left(T_{D D}-2 U_{N} \pi^{\prime}\right)-T_{D A}^{2}>0$. Thus the term in parenthesis in $(23)$ is strictly negative, and we can unambiguously sign $\frac{\partial R^{\star}}{\partial p}<0$, implying that the use of mainline roads declines as the price of gasoline increases.

Finally, we consider (22). In contrast to the previous two cases, we cannot unambiguously sign this term as the first term in parenthesis is positive, the second is negative, and the third is positive. Provided that the sum of the terms in parenthesis is negative, HOV lane use may actually increase as prices increase. Intuitively, this can occur because while HOV lane commuting looks worse relative to the alternative option when gas prices rise, HOV lane commuting looks better relative to mainline commuting. By contrast, the signs on the other commuter choices are clear higher prices make the alternative option look better relative to all other commuting choices, and higher prices make mainline commuting look worse relative to all other commuting choices. Thus, at least for the specific case here, the predictions of the formal household choice model mirror the predictions of the equilibrium sorting model developed in the main text.

\section{A.2 Robustness}

In this section we further investigate the robustness of our results along several dimensions. First, we investigate whether our results are driven by the possibility of non-stationary series in the flow data. Second, we explore estimation in semi-log and levels specifications as alternatives to our preferred double log model. Third, we estimate average elasticities using a series of models which incorporate increasingly flexible time trends intended to capture smooth changes in average traffic flows that might confound the estimated relationships between flow and prices.

Appendix table 1 shows results from our base model using the full sample of data. Column 1, shows estimates using our preferred model but limiting our sample to only station for which an Elliot-Rothenburg-Stock test on each series rejects the presence of a unit root in the station-level flow data. The third column uses only observations where we fail to reject the presence of a unit root. The parameter estimates are qualitatively similar across the three samples. However, the magnitude of the estimated effect of fuel prices on HOV lane flow is smaller when only stationary series are used and relatively larger when the I(1) series are used. The effects on the parameter estimates are the opposite for mainline lanes where the magnitudes of the point estimates are larger 
when only the stationary series are used. Overall however, the signs are consistent with the full sample effects. The point estimates for ML_HV and HOV lanes are statistically significant in all samples.

Next we explore implications of our assumed functional form. While we believe changes in fuel prices are most likely to have the same proportional effect across stations with substantially different mean flows, it is important to explore whether our results rely on a particular functional form. Appendix Table 2 shows the mean elasticities estimated using are base model and two alternate specifications. In the semi-log, the dependent variable is the natural logarithm of flow. Fuel prices enter in levels and imply a semi-elasticity interpretation for the fuel price coefficients. In the levels specification, both traffic flows and fuel prices enter in levels. Qualitatively, the results across all three models look similar. As in our main results, the effects in the mainline are negative and statistically significant. The point estimate for $\mathrm{ML} \_H V$ is larger in magnitude and statistically significant. For HOV lanes, the relationship between fuel prices and flows is positive and statistically significant. In model 3, the relationship between fuel prices and flows for ML_HV is negative and statistically significant. However, the estimate for ML is small, positive and not statistically significant. For HOV lanes, the relationship is positive and statistically significant.

At first glance, the mean flow responses in model 3 suggest a counterintuitive result that for a given change in fuel prices, HOV lane flow increases by approximately the same amount as mainline flow decreases. Of course if mainline drivers are forming carpools, we expect fewer than half of these vehicles to appear as additional vehicles in the HOV lane. ${ }^{45}$ We note two characteristics of the PeMS data which may contribute to the results in model 3. First, traffic detectors on mainline lanes tend to extend further from the city center compared with detectors in HOV lanes. Comparing sample means, flows for detectors in sections of the mainline where HOV flows are also monitored are approximately $5 \%$ larger than flows in outlying areas. This suggests our average flow elasticities may be biased downward if fuel prices result in proportional decreases in driving across the network. Second, PeMS engineers may locate traffic detectors more closely together on areas of freeway with high levels of flow and congestion. In addition, detectors may be spaced more closely together for HOV lanes compared with mainline lanes. To check this, we calculate the distance between detectors for each location in our sample. The correlation coefficient between spacing and flow is approximately -0.22 for HOV lanes and -0.16 for mainline lanes on highways with a HOV lane. It is approximately -0.002 for mainline lanes on other highways.

\footnotetext{
${ }^{45}$ All else equal. However, it may be possible that some drivers who form carpools switch from traveling on surface streets to freeways to take advantage of shorter travel times. This behavior may contribute somewhat to the size of the effects we estimate.
} 
In light of these potential issues, we estimate model 3 using a restricted sample that matches detectors in HOV lanes to detectors in mainline lanes in the same direction, on the same route. This has the benefit of excluding observations from mainline lanes on areas of the route where HOV lanes either do not exist or where traffic flows are not monitored. Furthermore, by matching stations one for one, we minimize complications due to the possibility that HOV flows are monitored more frequently in areas of high flow. In this restricted sample we estimate mean flow responses to fuel price changes of $-7,952$ in the mainline and 5,408 in HOV lanes. Furthermore, we cannot reject the hypothesis that the mainline response is twice as large and the HOV lane response. ${ }^{46}$

To make a more direct comparison between models and account for differences in mean flows across stations, Table 3 calculates the elasticities implied by the estimates in Table 2 evaluated at the conditional mean of the dependent variable. Comparing the log-log and semi-log models, the elasticities are strikingly similar. Compared with the preferred log-log specification, the mean elasticities implied by the levels specification are smaller in magnitude, though still qualitatively consistent with our main results.

Finally, we investigate robustness to inclusion of higher-order time trends. We use as our base case model 4 of Table 3 which includes a linear time trend. The models in Table 4 add polynomial trends to a maximum fifth-order. The average flow elasticity estimates for each of the three lanetypes are quite stable across the five models. The relative sizes and ranking of elasticities by lane type remains consistent across models and the parameter estimates are in general, all statistically significant.

\footnotetext{
${ }^{46}$ With a test statistic of $\mathrm{F}(1,79)=1.79$
} 


\section{Appendix Tables}

Appendix Table 1: Robustness of flow price relationships with and without non-stationary series.

\begin{tabular}{|c|c|c|c|}
\hline & Base Model & Excl. I(1) & I(1) Only \\
\hline In(Gasoline Price) $\times D_{M L}$ & $\begin{array}{c}-0.050 * * * \\
(0.0190)\end{array}$ & $\begin{array}{c}-0.066 * \\
(0.0340)\end{array}$ & $\begin{array}{c}-0.032 \\
(0.0200)\end{array}$ \\
\hline In(Gasoline Price) X $\mathrm{D}_{\mathrm{ML} \_\mathrm{HV}}$ & $\begin{array}{c}-0.083 * * * \\
(0.0100)\end{array}$ & $\begin{array}{c}-0.139 * * * \\
(0.0230)\end{array}$ & $\begin{array}{c}-0.063 * * * \\
(0.0110)\end{array}$ \\
\hline In(Gasoline Price) $\times D_{H V}$ & $\begin{array}{c}0.136 * * * \\
(0.0200)\end{array}$ & $\begin{array}{c}0.053 * * * \\
(0.0190)\end{array}$ & $\begin{array}{c}0.154 * * * \\
(0.0350)\end{array}$ \\
\hline Station Effects & Yes & Yes & Yes \\
\hline Week Effects & Yes & Yes & Yes \\
\hline Year Effects & Yes & Yes & Yes \\
\hline Observations & 339225 & 78834 & 260391 \\
\hline Adj. R-Squared & 0.99 & 0.99 & 0.99 \\
\hline \multicolumn{4}{|c|}{$\begin{array}{l}\text { Notes: Dependent variables are the natural logarithms of total weekly flow. Standard } \\
\text { errors clustered at the route-direction level in five mile intervals. Station week } \\
\text { observations with more than } 25 \text { percent imputation are dropped in each model. } \\
\text { Resuls in the second column exclude stations where Elliot-Rothenberg- Stock tests } \\
\text { fail to reject the presense of a unit root in traffic flow. The third column uses only } \\
\text { stations where we fail to reject the presence of a unit-root in the flow data. ***, ** } \\
\text { and } * \text { denote significance at the } 1 \text { percent, } 5 \text { percent and } 10 \text { percent levels. }\end{array}$} \\
\hline
\end{tabular}


Appendix Table 2: Robustness of flow price relationships under log-log, semi-log and levels specifications.

Relationships Between Flow and Prices With Respect to Functional Form

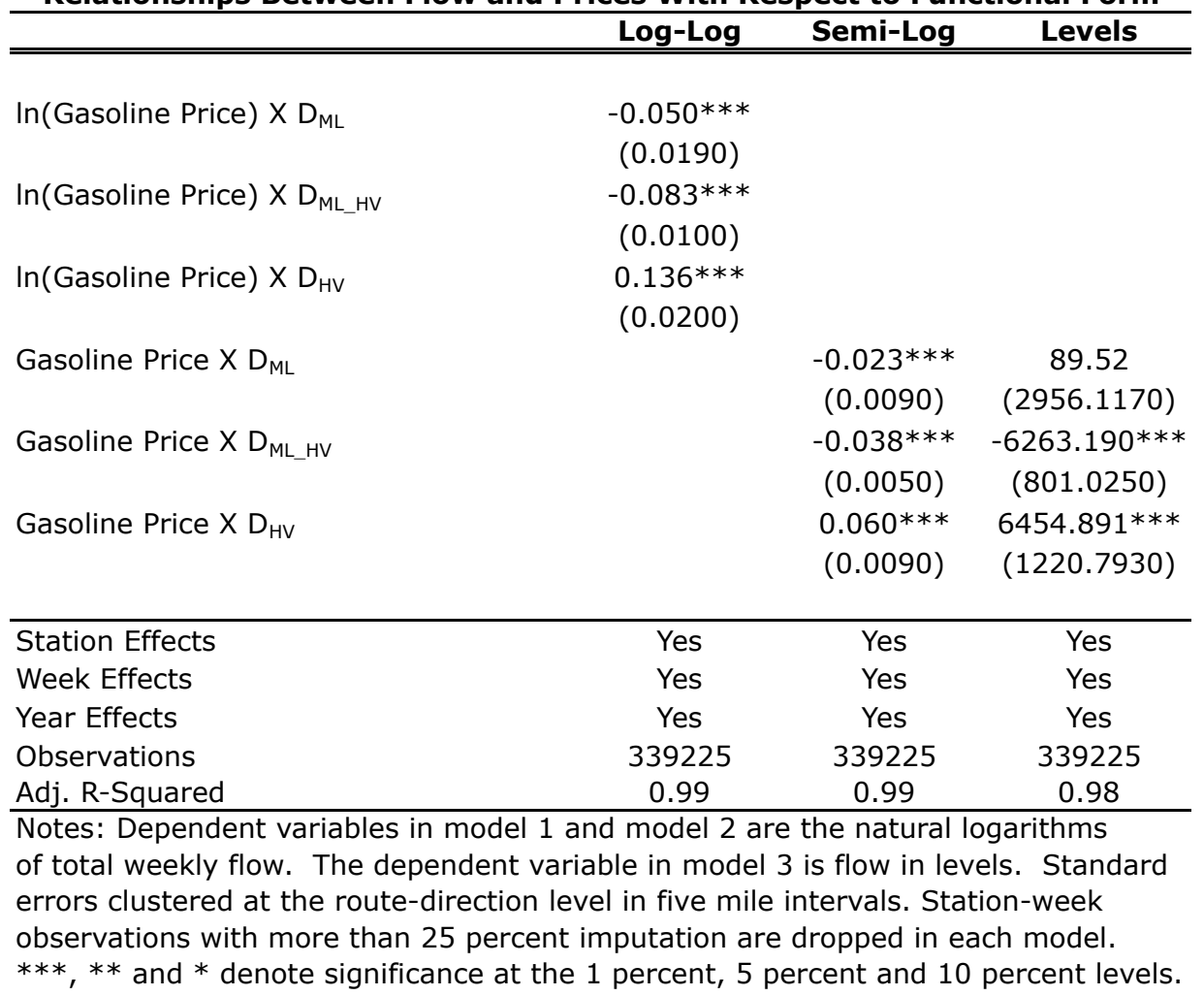


Appendix Table 3: Implied flow elasticities under log-log, semi-log and level specifications.

Flow Elasticities by Lane Type and Functional Form

\begin{tabular}{lccc}
\hline & Log-Log & Semi-Log & Levels \\
\hline \hline \multirow{2}{*}{ ML Elasticity } & $-0.050 * * *$ & $-0.052 * * *$ & 0.001 \\
& $(0.0193)$ & $(0.0194)$ & $(0.0213)$ \\
ML HV Elasticity & $-0.083 * * *$ & $-0.086 * * *$ & $-0.047 * * *$ \\
& $(0.0103)$ & $(0.0104)$ & $(0.0062)$ \\
HV Elasticity & $0.136 * * *$ & $0.137 * * *$ & $0.045 * * *$ \\
& $(0.0200)$ & $(0.0200)$ & $(0.0082)$
\end{tabular}

Notes: Flow elasticities in the semi-log and levels specifications are calculated at the conditional mean of the dependent variable. The dependent variables in the log-log and semi-log specifications are the natural logarithm of total weekly flow during weekday peak hours. Standard errors are reported in parentheses. $* * *, * *$ and $*$ denote significance at the 1 percent, 5 percent and 10 percent levels, respectively 
Appendix Table 4: Robustness of flow elasticity estimates for mainline lanes (ML), mainline lanes on highways with a HOV lane (ML HV), and HOV lanes for models incorporation time trends up to fifth-order.

Flow Elasticities by Lane Type Including Various Time Trends

\begin{tabular}{|c|c|c|c|c|c|}
\hline & First & Second & Third & Fourth & Fifth \\
\hline In(Gasoline Price) $\times D_{M L}$ & $\begin{array}{c}-0.098 * * * \\
(0.0210)\end{array}$ & $\begin{array}{c}-0.077 * * * \\
(0.0190)\end{array}$ & $\begin{array}{c}-0.031 \\
(0.0190)\end{array}$ & $\begin{array}{c}-0.031 \\
(0.0190)\end{array}$ & $\begin{array}{c}-0.054 * * * \\
(0.0190)\end{array}$ \\
\hline In(Gasoline Price) $\times D_{M L \_H V}$ & $\begin{array}{c}-0.129 * * * \\
(0.0120)\end{array}$ & $\begin{array}{c}-0.109 * * * \\
(0.0110)\end{array}$ & $\begin{array}{c}-0.063 * * * \\
(0.0100)\end{array}$ & $\begin{array}{c}-0.062 * * * \\
(0.0100)\end{array}$ & $\begin{array}{c}-0.087 * * * \\
(0.0090)\end{array}$ \\
\hline In(Gasoline Price) $\times D_{H V}$ & $\begin{array}{c}0.089 * * * \\
(0.0230)\end{array}$ & $\begin{array}{l}0.110 * * * \\
(0.0230)\end{array}$ & $\begin{array}{l}0.156 * * * \\
(0.0220)\end{array}$ & $\begin{array}{c}0.157 * * * \\
(0.0220)\end{array}$ & $\begin{array}{c}0.132 * * * \\
(0.0200)\end{array}$ \\
\hline Station Effects & Yes & Yes & Yes & Yes & Yes \\
\hline Week Effects & Yes & Yes & Yes & Yes & Yes \\
\hline Order of Time Trend Polynomial & $\mathrm{T}$ & $\mathrm{T}^{2}$ & $\mathrm{~T}^{3}$ & $\mathrm{~T}^{4}$ & $\mathrm{~T}^{5}$ \\
\hline Observations & 339225 & 339225 & 339225 & 339225 & 339225 \\
\hline Adj. R-Squared & 0.99 & 0.99 & 0.99 & 0.99 & 0.99 \\
\hline
\end{tabular}

Notes: Dependent variables are the natural logarithms of total weekly flow. Standard errors clustered at the routedirection level in five mile intervals. Station week observations with more than 25 percent imputation are dropped in each model. $* * *, * *$ and $*$ denote significance at the 1 percent, 5 percent and 10 percent levels, respectively. 